Research Article

\title{
Satellite-Based Assessment of Various Cloud Microphysics Schemes in Simulating Typhoon Hydrometeors
}

\author{
Ying Zhang, ${ }^{1}$ Yu Wang $\mathbb{D}^{1},{ }^{1}$ Guosheng Liu, ${ }^{2}$ Jianping Guo, ${ }^{3}$ Yuanjian Yang, ${ }^{4}$ Rui Li, ${ }^{1}$ \\ Yunfei Fu, ${ }^{1}$ and Liping Liu $^{3}$ \\ ${ }^{1}$ School of Earth and Space Sciences, University of Science and Technology of China, Hefei 230026, China \\ ${ }^{2}$ Department of Earth, Ocean and Atmospheric Science, Florida State University, Tallahassee, FL 32306-4520, USA \\ ${ }^{3}$ State Key Laboratory of Severe Weather, Chinese Academy of Meteorological Sciences, Beijing 100081, China \\ ${ }^{4}$ School of Atmospheric Physics, Nanjing University of Information Science and Technology, Nanjing 210044, China
}

Correspondence should be addressed to Yu Wang; wangyu09@ustc.edu.cn

Received 26 April 2019; Revised 11 July 2019; Accepted 31 July 2019; Published 7 October 2019

Academic Editor: Nir Y. Krakauer

Copyright (c) 2019 Ying Zhang et al. This is an open access article distributed under the Creative Commons Attribution License, which permits unrestricted use, distribution, and reproduction in any medium, provided the original work is properly cited.

\begin{abstract}
The accurate simulation of typhoon hydrometeors remains a challenge. This study attempts to evaluate the performances of five microphysics schemes (MPSs) in the Weather Research and Forecasting (WRF) model in simulating the supertyphoon Neoguri in July 2014. The observed microwave brightness temperature, as well as retrieved data from the microwave radiometer imager (MWRI) onboard Chinese FY-3B satellite, are used to test hydrometeor simulations. In particular, two MWRI radiance indices, including the emission index (EI) and scattering index (SI), are used to assess the performance of five MPSs in simulating liquid and frozen hydrometeors, respectively. Overall, the WRF model can well reproduce the overall pattern of typhoon-produced precipitation, albeit with slightly overestimated precipitation in the inner rainband and underestimated precipitation in the stratiform rainband. Moreover, ice water paths (IWPs) from all five MPS simulations are higher than those estimated from MWRI retrieval in most areas, and the spatial pattern and values of IWP for the National Severe Storms Laboratory double-moment MPS (NSSL) are much closer to those for MWRI. The NSSL scheme reproduces a more realistic joint histogram distribution of SI and EI than other MPSs do, relative to the observation. Besides, the nonlinear Lucas-Kanade optical flow approach has been used to reflect the horizontal distribution of hydrometeors in the typhoon. The results show that the simulated EI and SI from the five MPSs show a systematic southwest bias of approximately about $10 \sim 20 \mathrm{~km}$ and significant intensity bias in the convection area. Further model sensitivity tests confirm that the NSSL scheme generates more realistic graupel and supercooled water close to the observations among all MPSs. The findings suggest that satellite measurements would be helpful to assess MPSs in numeric weather models, especially for hydrometeor distributions in the whole typhoon system.
\end{abstract}

\section{Introduction}

Cyclone hydrometeors (e.g., cloud water, rainwater, cloud ice, snow, and graupel), which are related with the cyclone's diabatic heating and vertical velocity structure, are effective indicators of storm intensity [1]. For instance, the increases or decreases in specific frozen condensate amounts can dramatically modify the surface precipitation distribution of typhoons $[2,3]$. When evaporative cooling of cloud droplets and melting of ice particles are removed in the microphysics scheme (MPS), it produces much weaker simulated downdrafts, resulting in much stronger simulated hurricanes [4]. Besides, the terminal velocity of graupel is another factor in tropical cyclone simulation [5]. Generally, the variations in hydrometeors, which is important for tropical cyclone simulations, are largely modulated by the MPSs in models $[4,6-12]$.

Currently, the MPSs are increasingly available within numerical models such as the Weather Research and Forecasting (ARW-WRF) [13] model, ranging from single moment to double moment $[12,14]$. Since the doublemoment schemes have an advantage of greater flexibility in 
size distribution parameters and density assumptions as compared with single-moment approaches [15], they are often used in community research models in order to offer more faithful representations of the complex microphysical processes in a system [16, 17]. However, it is well established that, in some cases, double-moment schemes do not offer improved results over single-moment MPSs. For example, Van Weverberg et al. [18] evaluated mesoscale convective system simulations over the tropical western Pacific using three different MPSs and found that the performance of complex double-moment schemes demonstrated no superiority over the simpler single-moment schemes. In addition, considering that most of the existing cloud MPSs in mesoscale models are deduced from observations for midlatitude clouds, rather than from tropical cyclones [19], it remains unclear whether these MPSs related to hydrometeors are suitable and accurate enough in simulating or predicting cyclone. To improve tropical cyclone simulation, therefore, the performance of various MPSs should be compared and evaluated in a comprehensive way.

Until now, there are two ways for the assessment of MPSs based on satellite measurements. One is to directly evaluate model-simulated hydrometeors against the satellite-retrieved hydrometeors (e.g., [20]). This approach seems straightforward in an explicit way, albeit probably large uncertainties in satellite hydrometeor retrievals. Another is to compare satellite-observed radiances against those from model simulation. Particularly, satellite-observed microwave radiance, which can penetrate and provide insights into the vertical profiles of most cyclone hydrometeors, has great advantages in characterizing cyclone hydrometeors and evaluating various MPSs in simulation of tropical cyclone hydrometeors [21]. In addition, microwave radiance signals are sensitive to the assumed bulk density of graupel and ice cloud particle sizes produced by MPSs [22]. Here the model-simulated radiances are computed via radiative transfer models based on the simulated cloud, temperature, and humidity from numeric models (e.g., [19, 23]). In general, the radiance-based approach is superior in assessing hydrometeor output from models because the radiative transfer model is relatively more accurate in the simulation of radiances [24-29]. For a more comprehensive and reliable satellite-based assessment, we will combine the retrievalbased and radiance-based approach to assess the simulated typhoon hydrometeors in the present study.

The simulated hydrometeors vary significantly depending on the selected MPS in the models [19, 30]. More importantly, the performance of the current MPSs is still controversial in simulating hydrometeors of tropical cyclones. Therefore, the purpose of the present study is to assess the performance of different MPSs in simulation of hydrometeors in a supertyphoon case of Neoguri in 2014, using the measurements of new-generation polar orbiting satellite of Fengyun-3 (FY-3) [31, 32]. As the first supertyphoon of 2014, Neoguri occurred during 3-10 July 2014 with a minimum sea-level pressure of $918 \mathrm{hPa}$ and 1-minute maximum wind speed of $72 \mathrm{~m} / \mathrm{s}$ according to Joint Typhoon Warning Center (JTWC) reports. It was a large and powerful tropical cyclone, which directly struck Caroline Island,
Guam, and Japan $[33,34]$. The remaining of this article is organized as follows. In Section 2, the microwave brightness temperature (TB) observations from FY-3 satellite with relevant radiance indices, the WRF model and experiment design for typhoon simulations, the planeparallel microwave radiative transfer model (MWRT) $[35,36]$ for calculating model-based radiances, and the nonlinear Lucas-Kanade (LK) optical flow (OF) technique for comparisons are briefly described. The comparison results between observations and model simulations regarding the tracks, intensity, and surface precipitation rate of typhoon will be elaborated and discussed in Section 3. The retrieval-based and radiance-based evaluation of simulated typhoon hydrometeors are performed in Section 4, followed by discussions and conclusions in Sections 5 and 6 , respectively.

\section{Data and Methodology}

2.1. FY-3B Observation. As the second satellite in the FY-3 series of the new-generation polar-orbit meteorological satellite of China, the FY-3B satellite was launched on November 5, 2010, in an $831 \mathrm{~km}$ orbit with an inclination of $98.81^{\circ}$ and a period of $101.49 \mathrm{~min}$, and detailed descriptions can be found in previous studies [37]. As a passive microwave sensor onboard FY-3B, the microwave radiometer imager (MWRI) takes advantage of coincident data at five frequencies with both vertical and horizontal polarization channels: $10.65,18.7,23.8,36.5$, and $89 \mathrm{GHz}$ [37-39]. As shown in Table S1 of the supplementary material (SM), there are eight MWRI orbits in total (hereinafter referred to as 0703D, 0705A, 0705D, 0707A, 0707D, 0708A, 0708D, and 0709A) used to evaluate the hydrometeors of typhoon Neoguri in different evolution stages, including formation, developing, mature, and decaying. Moreover, based on the algorithm by Liu and Curry [40], the surface precipitation rate derived from MWRI was obtained to compare with the simulated surface precipitation rate. In addition, the simulated frozen precipitation hydrometeor (graupel and snow) path was compared to retrievals from the Microwave $\mathrm{Hu}-$ midity Sounder and MWRI [39]. Because raw brightness temperatures represent an integration of electromagnetic radiation information from emission and scattering by all of surface and atmospheric constituents, there is a considerable amount of ambiguity in directly interpreting raw brightness temperatures in terms of hydrometeor properties $[17,25,41]$. In order to establish the relationship between radiances and various hydrometeor more clearly, two particular radiance indices are used through quasilinear transformations of brightness temperatures on dual-polarization channels for specific frequency [41-43]. One is the emission index (EI), and the other is the scattering index (SI). Here EI is formulated as

$$
\mathrm{EI}=1-\frac{D}{D_{0}},
$$

where $D$ represents polarization difference between vertically and horizontally polarized brightness temperatures at 18.7 GHz ( 19) given by 


$$
D=\mathrm{TB}_{19 \mathrm{~V}}-\mathrm{TB}_{19 \mathrm{H}},
$$

and $D_{0}$ is the corresponding $D$ in the same scene but for clear-sky situation. It can be noticed that EI would vary from 0 to 1 , where small values indicate almost cloud-free field of view, while values near 1 denote opaque liquid clouds due to the strong emission effect at this frequency. As a result, EI is generally related to the content of liquid hydrometeors. On the contrary, SI can be expressed as

$$
\mathrm{SI}=2 \times\left(1-\frac{\mathrm{PCT}}{\mathrm{PCT}_{0}}\right),
$$

where PCT is the $89 \mathrm{GHz}$ polarization-corrected temperature defined by Spencer et al. [44] as

$$
\mathrm{PCT}=1.818 \mathrm{~TB}_{89 \mathrm{~V}}-0.818 \mathrm{~TB}_{89 \mathrm{H}},
$$

where $\mathrm{TB}_{89 \mathrm{~V}}$ and $\mathrm{TB}_{89 \mathrm{H}}$ are, respectively, vertically and horizontally polarized brightness temperatures at $89 \mathrm{GHz}$. Similar to $D_{0}, \mathrm{PCT}_{0}$ is that PCT at clear sky. In contrast to EI, SI represents the volume scattering effect associated with frozen precipitation hydrometeors left. Thus, a large value of SI indicates the occurrence of abundant solid hydrometeors $[25,43]$.

2.2. Model Configuration. In order to reveal the difference of hydrometeor simulations among various MPSs, the WRF (Version 3.6.1) [13] model with two-way interactive nesting is used to perform numerical simulations for typhoon Neoguri.

Three multiple-nested domains (Figure 1) were constructed, with horizontal grid spacings of 36,12 , and $4 \mathrm{~km}$, with corresponding numbers of grid points: $243 \times 264$, $463 \times 508$, and $1042 \times 1156$, respectively. The vertical height top was set to $50 \mathrm{hPa}$, and 36 vertical sigma layers were used in the WRF. The two outermost domains (D01 and D02) used five physics schemes: the Rapid Radiative Transfer Model for General Circulation Models scheme (RRTMG) [45] for longwave radiation, the RRTMG scheme for shortwave radiation, the Revised MM5 Monin-Obukhov scheme [46] for surface physics, the Yonsei University scheme (YSU) [47] for the boundary layer parameterization, and the Tiedtke cumulus parameterization scheme $[48,49]$. For the innermost domain (D03), the cumulus parameterization scheme was not used because that type of scheme is not designed for horizontal and vertical grid spacings smaller than about 5-10 km [50] as the typical scale of most convective clouds $[8,50]$.

The initial and boundary conditions used in the WRF model were interpolated from the National Centers for Environmental Prediction Final Operational Global Analysis data with $1^{\circ} \times 1^{\circ}$ spatial resolution and 6 hour temporal resolution. These initial parameters were inserted at 1200 UTC each day from 2 to 8 July 2014 and then integrated forward for 36 hours. Since the cyclone hydrometeor information is not included in the initial conditions, low-level convergence in these simulations would take some time to spin up from the large-scale circulation, and hence the models are not generally reliable for the first $12 \mathrm{~h}$ or so [51].
Therefore, only those outputs running after 12 hours are analyzed here.

2.3. Microphysics Schemes. For mesoscale modeling, most MPSs are bulk schemes that predict hydrometeor mass mixing ratios and/or number concentrations but assume size distributions based on empirical exponential or gamma distributions (e.g., [52-55]). In this paper, five different MPSs ranging from single moment to double moment were used in the WRF model, including the WRF Single-Moment 6-Class Scheme (WSM6) [56], the Goddard scheme (GSFC) [53], the Thompson scheme (THOM) [54], the Morrison double-moment scheme (MORR) [55], and the National Severe Storms Laboratory double-moment scheme (NSSL) [57].

Generally, there are certain differences in hydrometeor schemes among these five MPSs as follows. Both the WSM6 and GSFC, which mainly considered cloud water and ice as being the same uniform size, assumed spherical particles of constant density with an exponential size distribution as described by Lin et al. [52] and Rutledge and Hobbs [58]. Differently, the intercept parameter $\left(N_{\mathrm{ox}}\right)$ is fixed for all precipitating classes in the GSFC scheme, while the snow intercept parameter varied with a function of temperature in the WSM6 scheme (Table 1), according to the observations by Houze et al. [59]. In the THOM scheme, it was considered that nonspherical snowflake shape with bulk density varies inversely with diameter based on observations [60]; hydrometeor size distribution is represented by a combination of two gamma functions [61], which depended upon observed relationships between predicted snow mass and air temperature to calculate the size distribution moments. In addition, the intercept parameter for graupel varies with the mass of supercooled liquid [16]. For the NSSL scheme [57], it added a frozen hydrometeor-hail and employed double moments for considering a more robust treatment of the particle-size distribution (equations S2-S4 in SM). While hail generation occurs only with wet graupel, the hail category was not dominated by high-density ice. Therefore, graupel particles in the NSSL scheme can range from frozen drops to low-density graupel, while there are only negligible amount of hail in the simulated typhoon of NSSL. Finally, for the MORR scheme, it took account for more complicated rain size distributions with different rates of rain evaporation in stratiform and convective regions. Besides, the MORR scheme has options to optimize simulations by accommodating the selection of ice nucleation methods and CCN spectra [62]. Further details of these MPSs are shown in Table 1 and in SM.

2.4. Microwave Radiative Transfer Simulations. To examine the capability of the various MPSs in replicating the microphysical cloud properties observed by the FY-3B MWRI, the model output fields from the WRF including hydrometeor simulations were incorporated into the MWRT model $[15,35,36]$. As such, the model-equivalent MWRI radiance $\mathrm{TB}$ at $18.7 \mathrm{GHz}$ and $89.0 \mathrm{GHz}$ frequencies was obtained on model grids. Besides, the extinction and 


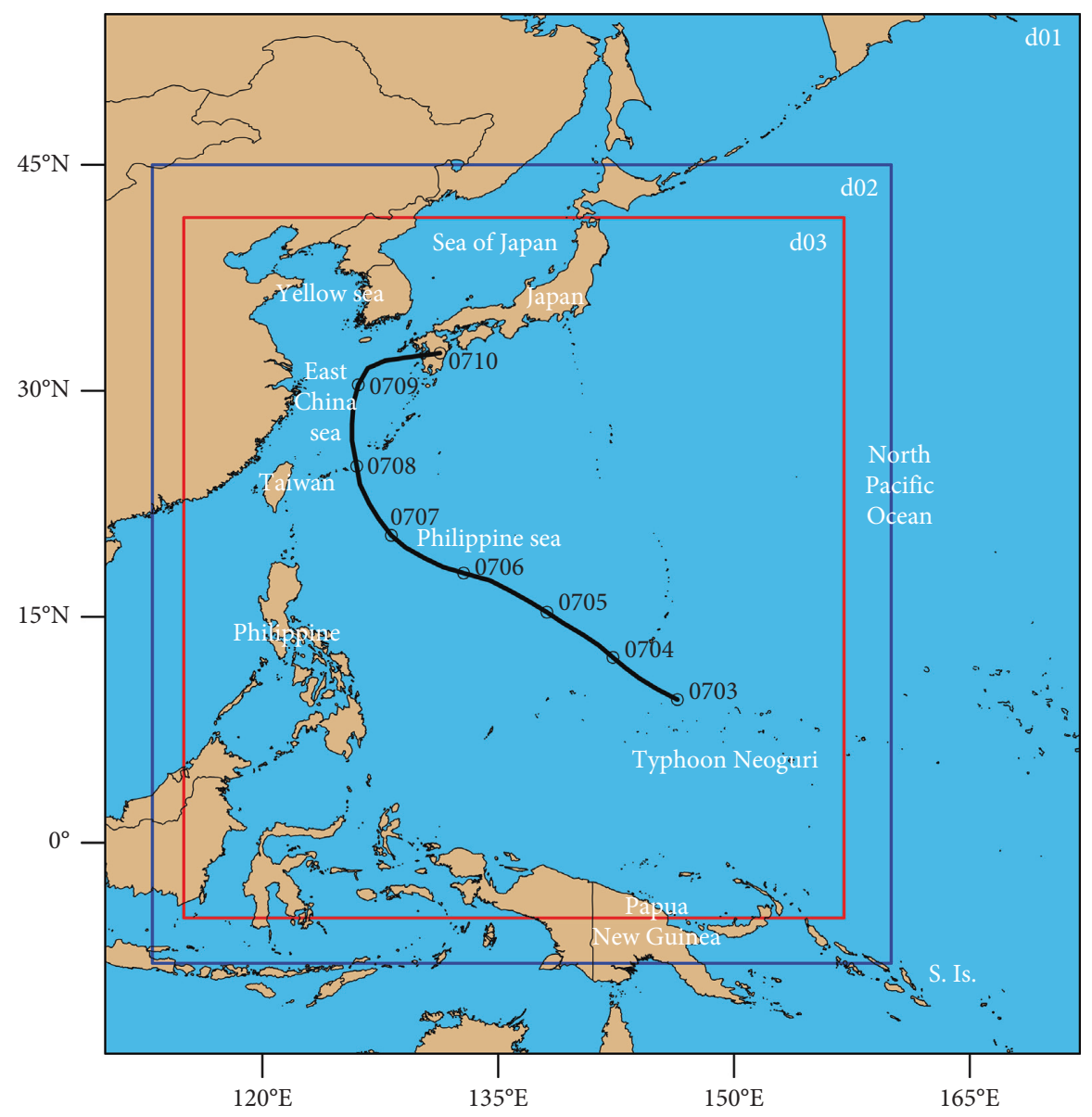

FIGURE 1: Three two-way nested domains used for numerical simulations of supertyphoon Neoguri (2014) in WRF. Horizontal resolutions for domains $\mathrm{d} 01, \mathrm{~d} 02$, and $\mathrm{d} 03$ are 36,12 , and $4 \mathrm{~km}$, respectively. The JTWC track of typhoon Neoguri also is present.

Table 1: Particle-size distribution (PSD) and density assumptions for precipitation hydrometeor species.

\begin{tabular}{|c|c|c|c|c|c|c|c|c|c|c|c|c|}
\hline \multirow{3}{*}{$\begin{array}{l}\text { Scheme } \\
\text { (\# of moments) }\end{array}$} & \multicolumn{8}{|c|}{ PSD } & \multirow{2}{*}{\multicolumn{4}{|c|}{ Bulk density $\left(\mathrm{kg} \cdot \mathrm{m}^{-3}\right)$}} \\
\hline & \multicolumn{4}{|c|}{$\alpha x$} & \multicolumn{4}{|c|}{$N_{\mathrm{ox}}\left(\mathrm{m}^{-1} \cdot \mathrm{m}^{-3}\right)$} & & & & \\
\hline & $\mathrm{Ra}$ & Sn & $\mathrm{Gr}$ & $\mathrm{Ha}$ & $\mathrm{Ra}$ & $\mathrm{Sn}$ & $\mathrm{Gr}$ & $\mathrm{Ha}$ & $\mathrm{Ra}$ & Sn & $\mathrm{Gr}$ & $\mathrm{Ha}$ \\
\hline WSM6 (1) & 0 & 0 & 0 & - & $8 \times 10^{6}$ & $N_{\text {os }}(T)$ & $4 \times 10^{6}$ & - & 1000 & 100 & 500 & - \\
\hline GSFC (1) & 0 & 0 & 0 & - & $8 \times 10^{6}$ & $1.6 \times 10^{7}$ & $4 \times 10^{6}$ & - & 1000 & 100 & 400 & - \\
\hline THOM (half 2) & 0 & NA & 0 & - & $N_{0 \mathrm{r}}(T)$ & NA & $N_{0 \mathrm{~g}}(T)$ & - & 1000 & not a const & 400 & - \\
\hline MORR (2) & 0 & 0 & 0 & - & $N_{0 \mathrm{r}}(n, q)$ & $N_{0 \mathrm{~s}}(n, q)$ & $N_{0 \mathrm{~g}}(n, q)$ & - & 997 & 100 & 400 & - \\
\hline NSSL (2) & 0 & NA & 0 & 2 & NA & NA & NA & NA & 1000 & 100 & $300-900$ predicted & 500-900 predicted \\
\hline
\end{tabular}

$\alpha$ is the shape factor for the gamma function; $N_{\mathrm{o}}$ is the intercept parameter; NA indicates not available; Ra, Sn, Gr, and Ha stand for rain, snow, graupel, and hail, respectively.

scattering properties of the hydrometeors were determined based on the Mie calculation. To ensure data consistency, the simulated TBs were further interpolated to the MWRI swath resolution for pixel-by-pixel comparison.

2.5. Nonlinear Lucas-Kanade Optical Flow Approach. The verification method of optical flow (OF) attempts to address whether two fields (e.g., the observed and simulated fields) agree with each other by inferring the mapping function. The mapping provides a visual summary of the "difference" between the two fields [62], which is a technique developed to assess the quality of simulated spatial fields. The notion of an OF is broad. Many variants take a purely algorithmic or nonparametric approach (e.g., [63]), capable of modeling a wide range of flow patterns [64]. Among others, one variant of the OF verification approach called Lucas-Kanade (LK)OF allows for analytic solutions in an objective way $[65,66]$. LK-OF has the merit of simultaneously estimating three components of errors for a given simulated variable, 
including its intensity, the direction, and distance of displacement [64]. The original LK-OF formulation was linear; then, in order to provide more accurate estimates of the errors, Marzban and Sandgathe [64] extended it into a nonlinear formulation. Here, this nonlinear LK-OF approach is employed to compare the observed and simulated radiance indices of EI and SI. Details of the formulas are provided in SM. On the contrary, when carrying out the comparison in the LK-OF approach, both the observed and the simulated TBs were regridded to $0.2^{\circ} \times 0.2^{\circ}$ resolution.

\section{Typhoon Track, Intensity, and Surface Precipitation Simulation}

3.1. Typhoon Tracks. The simulation of the typhoon track plays an important role in typhoon modeling studies, as it is the basis for simulating structures of typhoon surface precipitation and cloud hydrometeors. The track errors might be made by the inaccuracy of balanced initial conditions, absence of favorable environmental variables, and/or inadequacy in the other physical processes. Figure 2(a) shows that all five simulated tracks resembled the best track archived by JTWC in most of the typhoon life cycle, except for the formation stage. As illustrated in Table S2 of SM, the simulated typhoons by all the five schemes moved slightly faster than JTWC, which probably is caused by the different azimuthal organizations of convection and precipitation patterns $[1,67]$. In Figure 2(b), though MORR produces a relatively better track simulation and has a minimum average error of $69.5 \mathrm{~km}$ and a minimum standard deviation of $42.2 \mathrm{~km}$ (more statistics can be shown in Table S3), it could be seen that the track simulation for typhoon Neoguri was little sensitive to the choice of MPS.

3.2. Typhoon Intensity. Figure 3 shows the time series of mean sea level pressure (MSLP) and maximum surface wind speed (MWS) for JTWC and simulations, respectively. Also, the peak intensity and corresponding peak time of them are shown in Table 2. For simulated MSLP, in all five schemes, the time reaching peak intensity lagged behind the observation (JTWC), and the typhoon intensity was overestimated after 1200 UTC 7 July when Neoguri began to decay. Relatively, the peak times of NSSL were much closer to the observed values, probably because of the low-simulated translational speed mentioned above. For simulated MWS, all five schemes obviously overestimated MWS during the formation and early development stages (3-4 July). For rapid development and mature stages, WSM6, GSFC, and MORR slightly underestimated it, while NSSL and THOM perform better.

In addition, MSLP and MWS from the WSM6 and GSFC, respectively, are quite similar to each other. Such notable consistent results might be caused by fixing one or several parameters in the semiempirical description of PSD [68]. The aforementioned results, based on simulated track and intensity, show that the simulations based on doublemoment MPS (NSSL and MORR) were somewhat superior to those of the single-moment or partial double-moment
MPS (WSM6, GSFC, and THOM). The double-moment MPS offered more faithful representations of the complex microphysical processes in the given weather system [16]. Specially, it can be noted that NSSL more closely matched the JTWC estimates.

3.3. Surface Precipitation. The spatial distribution of simulated surface precipitation is shown in Figure 4, along with that obtained from the FY-3B-MWRI overpass time instances during the different stages of the typhoon life cycle. In general, the simulated precipitation amounts could capture the trends represented in the observed precipitation. For the precipitation pattern, however, the observed precipitation was mainly concentrated in domains within a radius of about $400 \mathrm{~km}$ from the cyclone center during the rapid intensification to the early decaying stage (05/07-08/07), while the associated spatial extent of simulated surface precipitation was slightly larger, and also more isolated precipitation clusters can be found in the all the simulations, especially for WSM6 and GSFC.

Moreover, it is notable that the simulated typhoon exhibited systematically wetter conditions over the strong convective activity areas of the inner rainband than observed, whereas for the outer spiral rainbands, the simulation was noticeably drier, and the diversities in the outlying spiral rainband regions were significant among different MPSs. Given that the strength of northwest Pacific cyclone intensity was remarkably well correlated with surface precipitation within the inner cores of the cyclone [69], it may have led to a simulated typhoon stronger (lower MSLP) than the observed one (JTWC). By comparison, the results of NSSL, with a relatively weaker and smaller distribution of graupel hydrometeor path at the surface precipitation extension (Figure S1 of SM), were generally closer to the observations than those of the other schemes. As showed in Figure S1 of SM, we also note that the spatial distribution pattern of graupel for individual simulation times closely resembled the intense precipitation location, implying that graupel hydrometeors had higher density and faster fall speeds to reduce their losses induced by evaporation and to shorten the residence time of the hydrometeor and thus modulated the surface precipitation $[1,70]$. In general, the NSSL scheme's propensity for graupel production likely explains the ability of this scheme to produce the spatial extent of the precipitation regions.

\section{Evaluation of Simulated Hydrometeors in Typhoon Neoguri}

In this section, one typical case in the strong stage of typhoon Neoguri on 05/07/2014, fully captured by FY-3BMWRI, as shown in Figure 4(g), was chosen for further evaluating the simulated hydrometeors with different MPSs by combining the retrieval-based and radiance-based approaches.

4.1. Retrieval-Based Approach and Comparison of Simulated Hydrometeors. Considering the difficulty in retrieving 


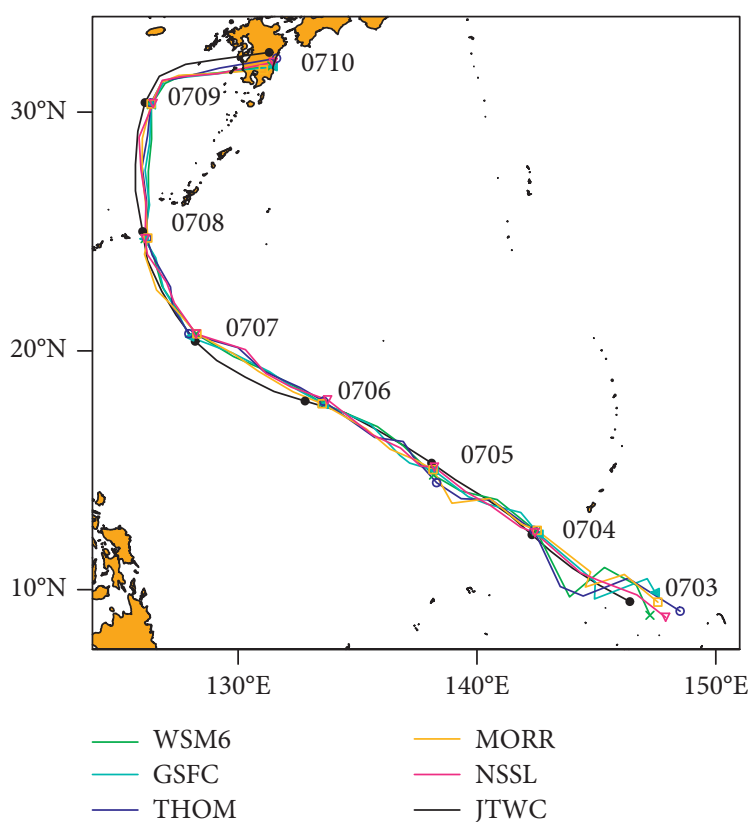

(a)

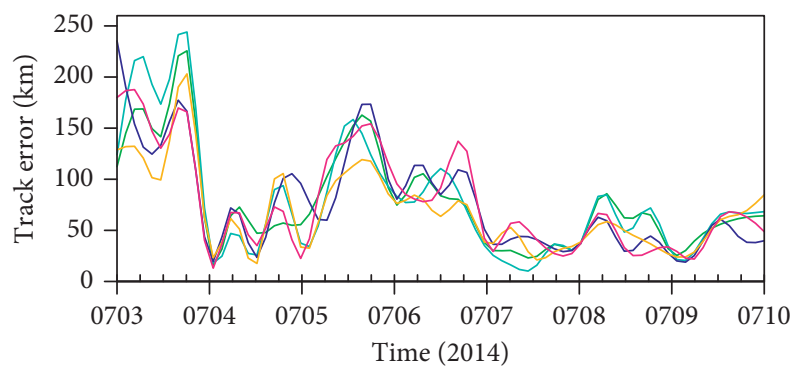

(b)

FIGURE 2: Spatial distribution of the typhoon track from model simulations during 0000 UTC 3 Jul to 0000 UTC 10 July 2014 at 6 h intervals, compared with (a) the JTWC best-track data and (b) the corresponding time series of simulated track errors with respect to the best track from JTWC. The simulations began at 1200 UTC each day from 2 to 8 July 2014 and then integrated forward for 36 hours, with 12 -hour spinup time.

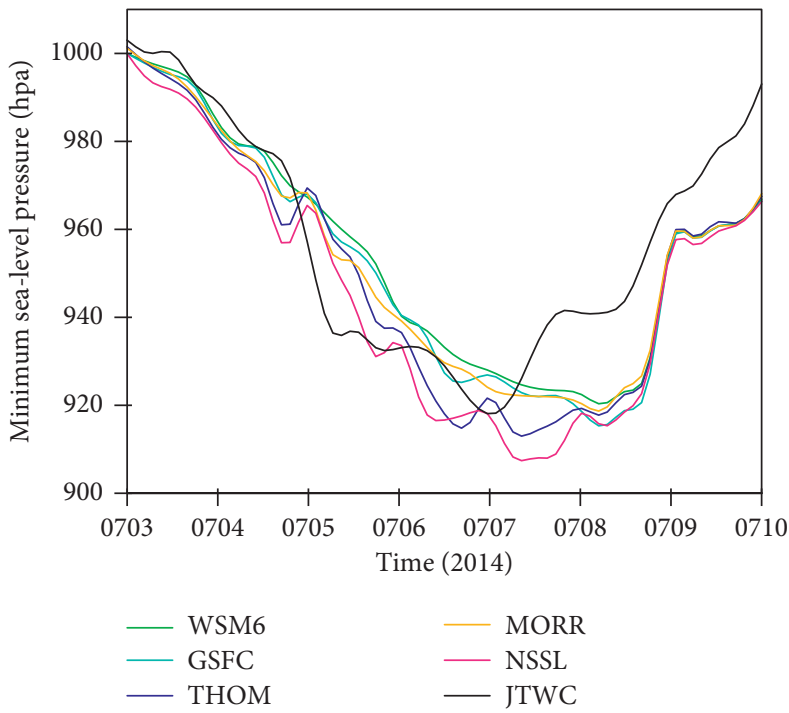

(a)

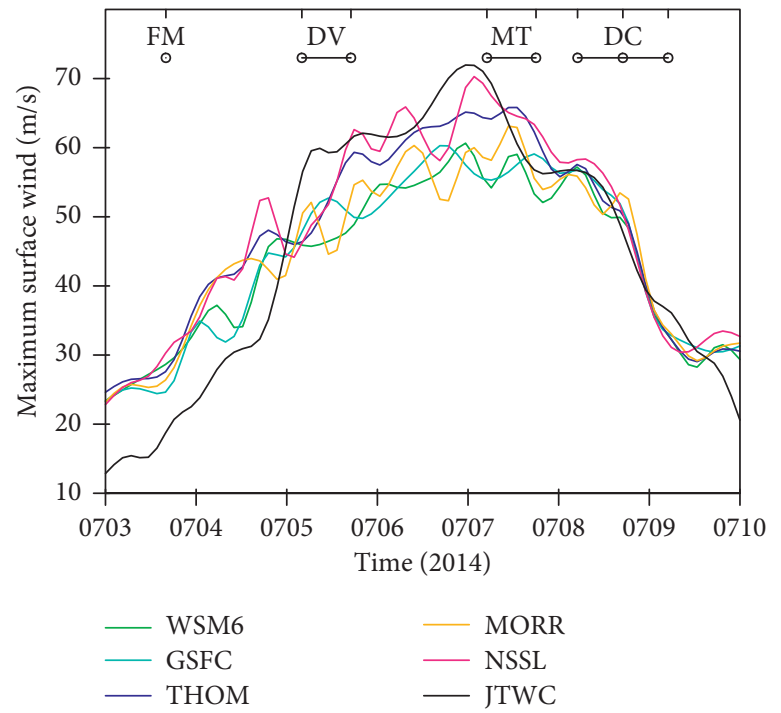

(b)

FIGURE 3: Comparisons of the intensity of typhoon Neoguri during 0000 UTC 3 July to 0000 UTC 10 July 2014 at 6 h intervals: (a) minimum sea level pressure (MSLP) and (b) maximum surface wind speed (MWS), for the best track (JTWC) and the model simulations. The black solid lines indicate JTWC; the green curves, WSM6; the cyan curves, GSFC; the blue curves, THOM; the golden curves, MORR; and the pink curves, NSSL. At the top of panel (b), the times of the FY-3B observations are shown by short lines. The stages defined in this study (see text) are also shown at the top as FM (formation), DV (developing), MT (mature), and DC (decaying). The simulations began at 1200 UTC each day from 2 to 8 July 2014 and then integrated forward for 36 hours, with 12-hour spin-up time.

liquid water content for cyclone due to the complexity of microwave signals about liquid precipitation particles, only simulated frozen precipitation path including graupel and snow as ice water path (IWP) is directly evaluated here (Figure 5). It can be seen that simulated IWPs in all schemes are higher than that by retrieval in most areas, especially in 
TABLE 2: Statistics of minimum sea level pressure (MSLP) and maximum surface wind speed (MWS) from the simulation using five MPSs, combined with JTWC for the supertyphoon Neoguri occurring in July 2014.

\begin{tabular}{lcccc}
\hline & & & & MWS \\
& Min. (hPa) & $T$ (day-hour) & Max. (m/s) & $T$ (day-hour) \\
\hline WSM6 & 920.3 & $08-06$ & 60.4 & $07-00$ \\
GSFC & 915.2 & $08-06$ & 60.4 & $06-18$ \\
THOM & 914.1 & $07-12$ & 65.9 & $07-12$ \\
MORR & 918.9 & $08-06$ & 63.5 & $07-12$ \\
NSSL & 908.0 & $07-12$ & 69.5 & $07-00$ \\
JTCW & 918 & $07-00$ & 72.0 & $07-00$ \\
\hline
\end{tabular}

$T$ denotes the time (UTC) with peak intensity for the typhoon.

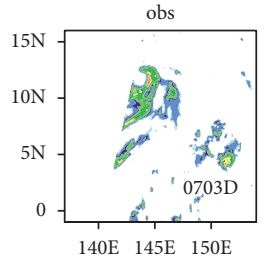

(a)

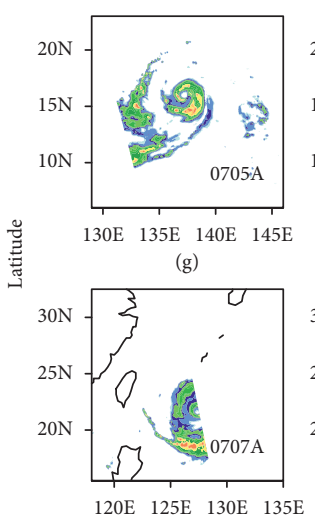

(m)

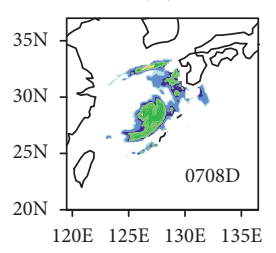

(s)

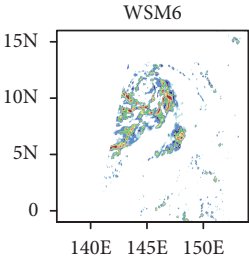

(b)

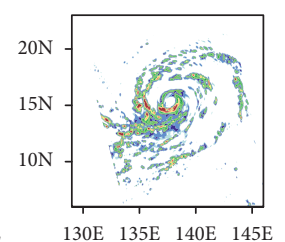

(h)
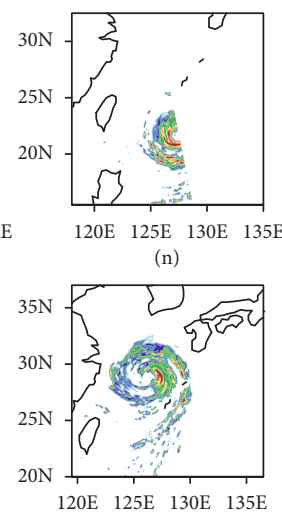

(t)

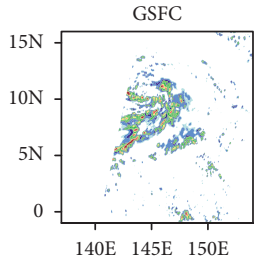

(c)

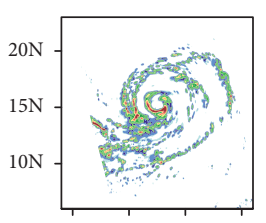

$130 \mathrm{E} \quad 135 \mathrm{E} \quad 140 \mathrm{E} \quad 145 \mathrm{E}$

(i)

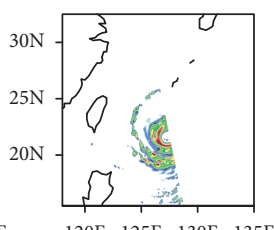

(o)

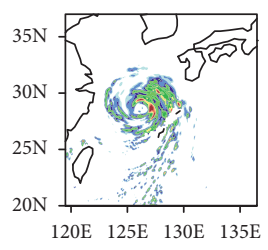

(u)

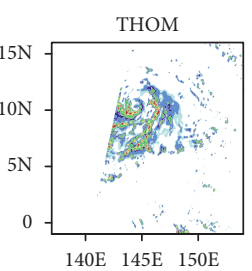

(d)

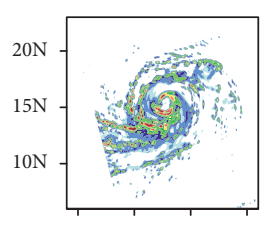

(j)

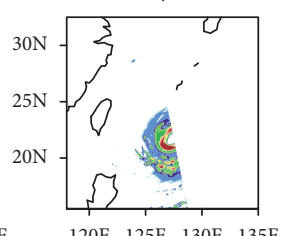

(p)

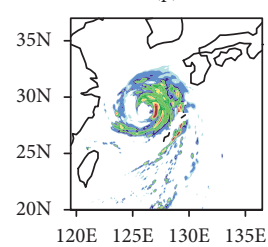

(v)

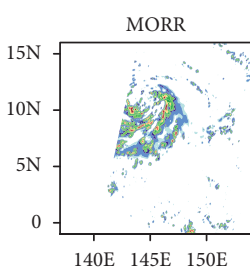

(e)

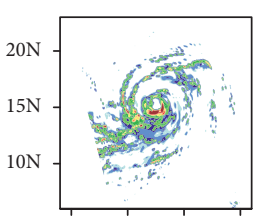

$130 \mathrm{E} \quad 135 \mathrm{E} \quad 140 \mathrm{E} \quad 145 \mathrm{E}$ (k)

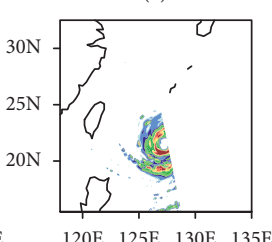

(q)

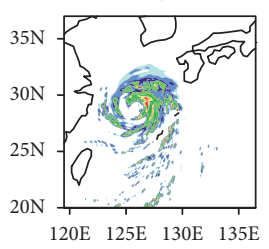

(w)
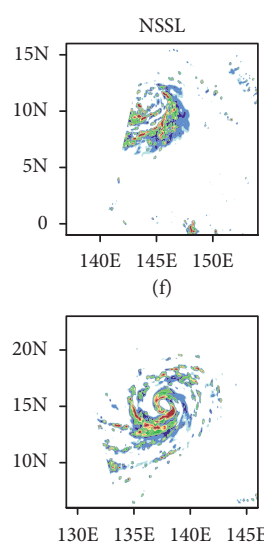

(1)

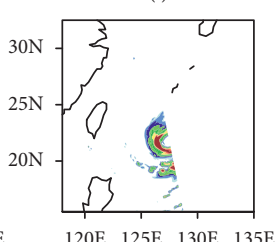

(r)

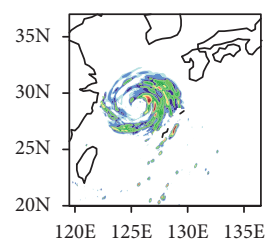

(x)

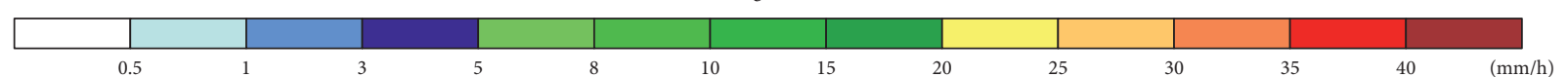

FIGURE 4: Horizontal distribution of FY-3B-MWRI (first column) retrieved and model-simulated surface precipitation rate (mm/h) produced with the supertyphoon Neoguri, using the cloud microphysical schemes of WSM6 (second column), GSFC (third column), THOM (fourth column), MORR (fifth column), and NSSL (sixth column). Note that the first to fourth rows correspond to the time of FY-3B overpasses of 0703D, 0705A, 0707A, and 0708D.

outside areas (e.g., spiral cloud belts). Comparatively, the IWP spatial pattern and values for NSSL and WSM6 are generally closer to those for FY-3B MWRI, vice versa, for THOM. Moreover, as indicated by white circles in Figure 5, IWP statistics in $1^{\circ}$ radius inner-core zone, $1^{\circ}$ radius $\sim 2.5^{\circ}$ radius middle-annular zone, and $2.5^{\circ}$ radius $\sim 4^{\circ}$-radius outside-annular zone are given in Table 3 , respectively. Obviously, the retrieved IWPs within inner-core and middle-annular zones (1554 and $1002 \mathrm{~g} \mathrm{~m}^{-2}$ ) are obviously higher than those within the outside-annular zone $\left(405 \mathrm{~g} \mathrm{~m}^{-2}\right)$. However, for all the MPSs, no such apparent IWP decrease from the inside zone to outside zone can be found. The IWP values for NSSL are closer to those retrieved by FY-3B MWRI, especially within inner-core and outsideannular zones, probably due to less graupel contents (refer to Figure 5 and Table S4 in SM). A potential explanation is that NSSL uses adaptive sedimentation to allow some size sorting and to prevent spurious large particles, which can arise in the 

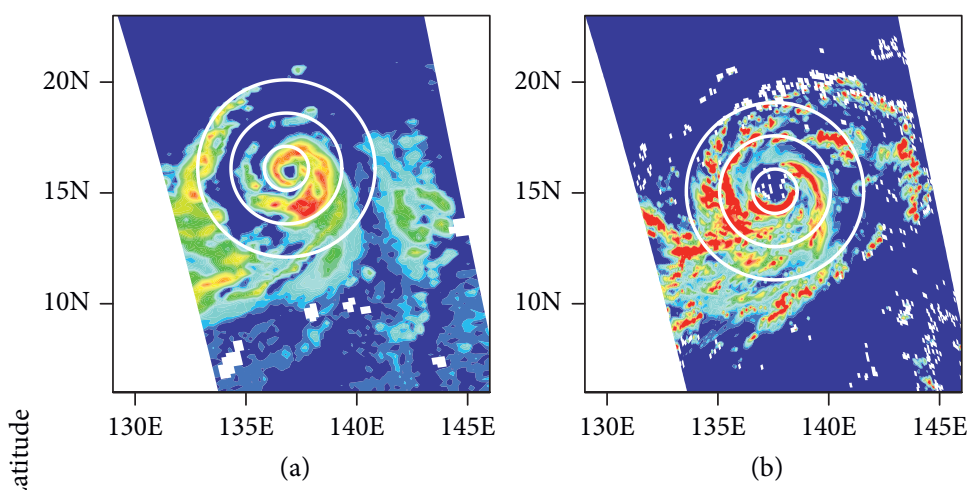

(b)

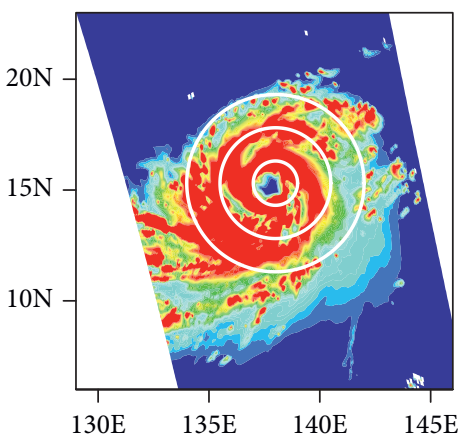

(d)

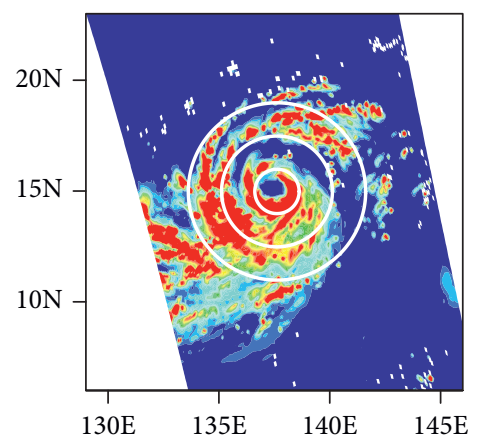

(e)

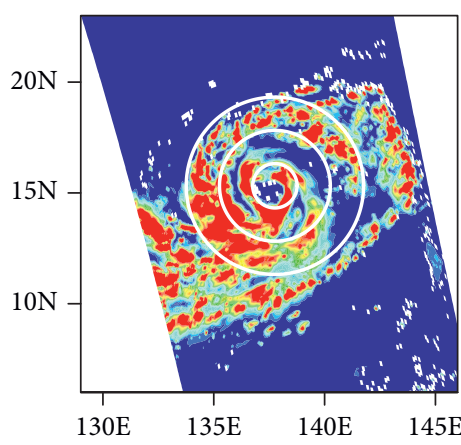

(c)

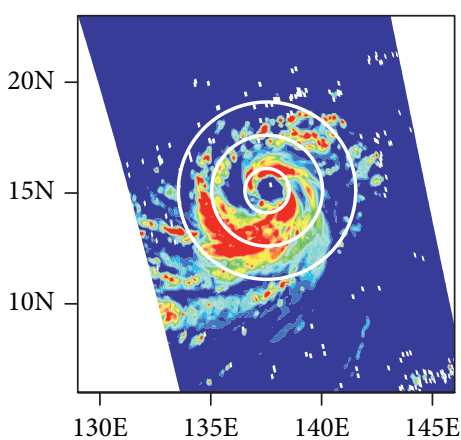

(f)

Longitude

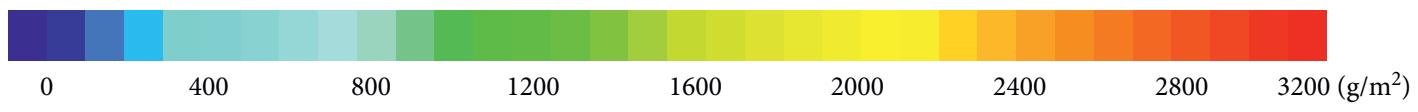

FIGURE 5: Horizontal distribution of FY-3B retrieved IWP (a) and model-simulated frozen precipitation (graupel and snow) produced with the supertyphoon Neoguri, using the cloud microphysical schemes of (b) WSM6, (c) GSFC, (d) THOM, (e) MORR, and (f) NSSL, based on matched instances of $0705 \mathrm{~A}$. Three white rings are $1^{\circ}, 2.5^{\circ}$, and $4^{\circ}$ radius annuli, respectively.

TABLE 3: Statistics of the domain-averaged frozen precipitation path $\left(\mathrm{g} \mathrm{m}^{-2}\right)$ in sample by the annular region, from the simulation using five MPSs, combined with FY-3B retrieval ice water path (IWP; $\mathrm{g} \mathrm{m}^{-2}$ ), based on the matched instances of $0705 \mathrm{~A}$.

\begin{tabular}{lcccccc}
\hline & \multicolumn{3}{c}{ Frozen precipitation path } & \multicolumn{3}{c}{ Ice water path } \\
& WSM6 & GSFC & THOM & MORR & NSSL & FY3B \\
\hline $1^{\circ}$ inner-core zone & 2378 & 2964 & 5041 & 3072 & 1786 & 1554 \\
$1^{\circ} 2.5^{\circ}$ middle-annular zone & 1816 & 2524 & 5280 & 2304 & 1871 & 1002 \\
$2.5^{\circ} \sim 4^{\circ}$ outside-annular zone & 1188 & 2429 & 3654 & 2215 & 1101 & 405 \\
\hline
\end{tabular}

larger precipitation hydrometeors [16, 57]. Over all three areas, THOM produces the largest amount of IWPs, among all the schemes, mainly in the form of snow (Figures 6 and S2 in SM; Tables 3 and S4). Wheatley et al. [16] found that falling speed made a large contribution on the sensitivity to precipitation hydrometeors with respect to the corresponding MPS, and the disparity in the snowfall speeds between the THOM (slower) and NSSL (faster) MPSs may account for the different evolutions of snow fields.

In general, compared with retrieved IWP, all simulated IWPs of five MPSs are systematically overestimated over all three areas, except for the NSSL over the inner-core zone. These noticeable distinctions in the simulated hydrometeors of various MPSs are highlighted by the vertical cross sections of time-domain ensemble means of cloud water, rainwater, cloud ice, snow, and graupel hydrometeor contents, within a radius of $400 \mathrm{~km}$ from the typhoon center, from 0000 to 2400 UTC 5 July 2014 (Figure 6). More detailed comparison of hydrometeors among five MPSs can be found below.

The evident differences in the five MPSs are the distributions of liquid hydrometeors (cloud water and rainwater) at high altitudes, especially above $5 \mathrm{~km}$ (i.e., supercooled water). In the NSSL simulations, supercooled water of $0.02 \mathrm{~g} \mathrm{~m}^{-3}$ is at about the $-40^{\circ} \mathrm{C}$ level, i.e., $\sim 12 \mathrm{~km}$ horizontally extended over $300 \mathrm{~km}$ radius wide in the convective region (Figure 6(e)), whereas the magnitudes of supercooled water contents were relatively smaller in the other MPSs. Based on the combination of radar, passive microwave, and lightning observations, Cecil and Zipser [71] proposed that supercooled water occurs preferentially in outer rainbands, compared to other tropical oceanic precipitation. Meanwhile, Cecil and Zipser [71] and Reinhart et al. [72] also 


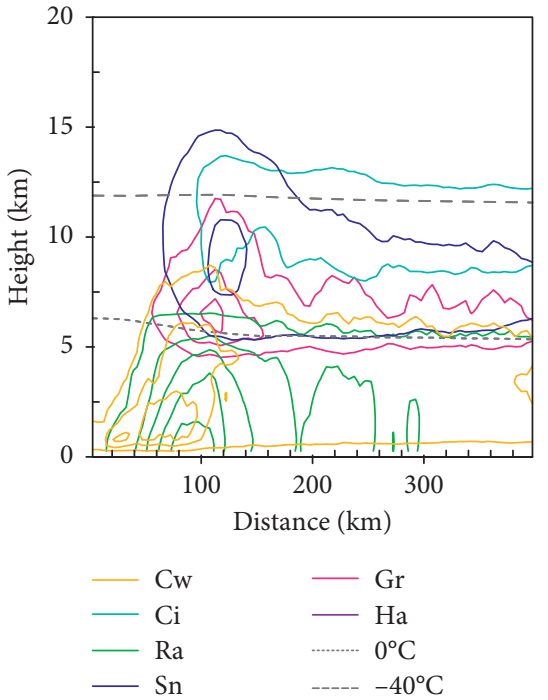

(a)

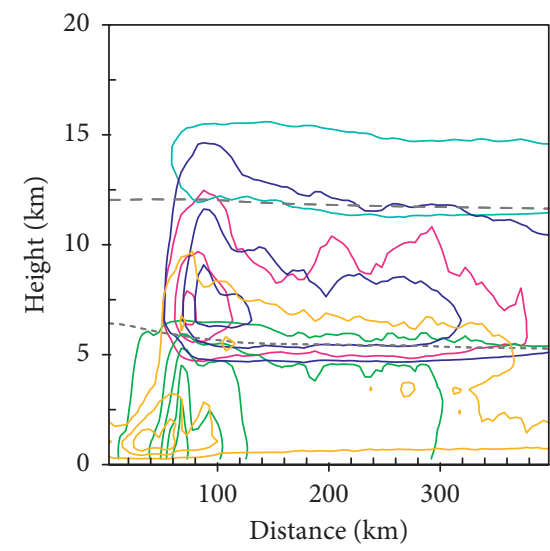

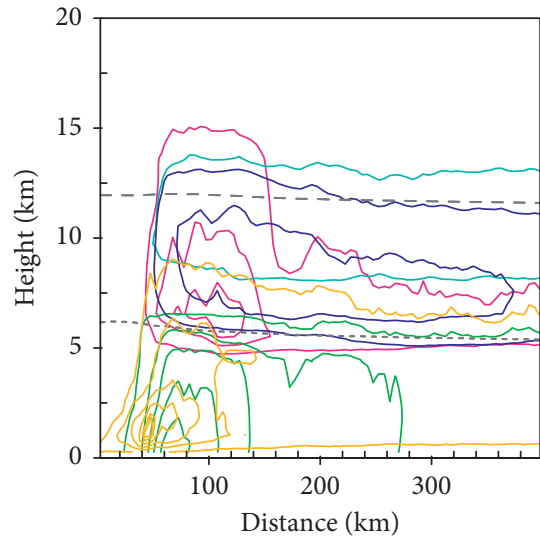

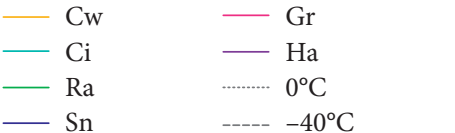

(b)

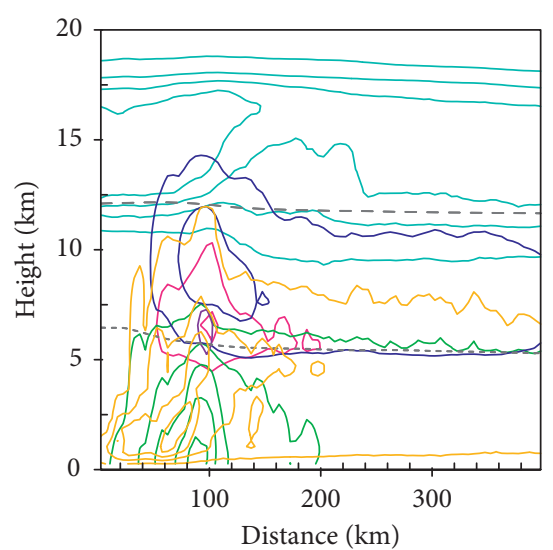

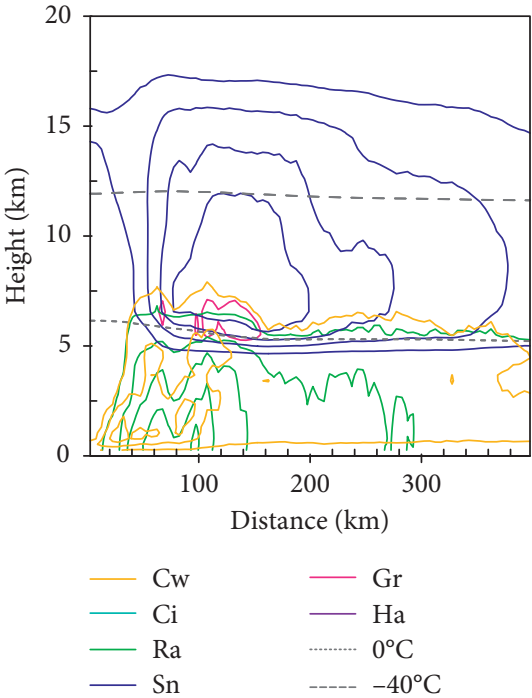

(c) (d)

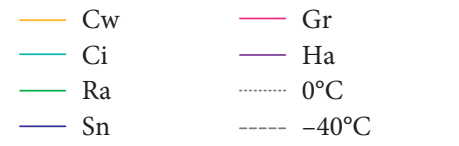

(e)

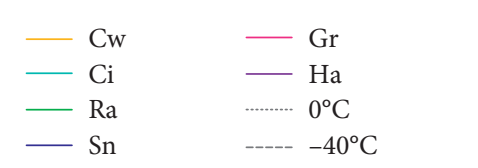

FiguRE 6: Vertical cross sections of time-domain ensemble mean of cloud water content (Cw; orange contour lines; every $0.1 \mathrm{~g}^{-3}{ }^{-3}$, starting at $0.02 \mathrm{~g} \mathrm{~m}^{-3}$ ), rain water content (Ra; green contour lines; every $0.2 \mathrm{~g} \mathrm{~m}^{-3}$, starting at $0.02 \mathrm{~g} \mathrm{~m}^{-3}$ ), cloud ice content (Ci; cyan contour lines; every $0.05 \mathrm{~g} \mathrm{~m}^{-3}$, starting at $\left.0.02 \mathrm{~g} \mathrm{~m}^{-3}\right)$, snow water content ( $\mathrm{Sn}$; blue contour lines; every $0.1 \mathrm{~g} \mathrm{~m}^{-3}$, starting at $0.2 \mathrm{~g} \mathrm{~m}^{-3}$ ), graupel water content (Gr; pink contour lines; every $0.1 \mathrm{~g} \mathrm{~m}^{-3}$, starting at $0.2 \mathrm{~g} \mathrm{~m}^{-3}$ ), and hail water content (Ha; purple contour lines; every $0.005 \mathrm{~g} \mathrm{~m}^{-3}$, starting at $0.01 \mathrm{~g} \mathrm{~m}^{-3}$ ); the gray dot-dash lines indicate $0^{\circ} \mathrm{C}$ contour lines; gray short-dash lines indicate $-40^{\circ} \mathrm{C}$ temperature contour lines; from 0000 to 2400 UTC 5 July 2014, within a radius of $400 \mathrm{~km}$ from the cyclone center, for (a) WSM6, (b) GSFC, (c) THOM, (d) MORR, and (e) NSSL.

suggested that supercooled water occurs at a height of about 11 to $12 \mathrm{~km}\left(\sim-40^{\circ} \mathrm{C}\right)$ in the Tropical Cyclone cloud band. These observations indicate that NSSL can reproduce a more realistic vertical structure of supercooled water than do the other MPSs. In addition, the rainwater contents of GSFC, WSM6, THOM, and MORR were all similar, while the content for the NSSL was slightly lower than the others.

For cloud ice, the simulation using NSSL/MORR MPS was characterized by more cloud ice in the upper levels. It is evident that cloud ice from the simulations of NSSL and MORR schemes is clearly characterized at a higher altitude
$(>12 \mathrm{~km})$.While only negligible amounts of cloud ice $\left(<0.02 \mathrm{~g} \mathrm{~m}^{-3}\right)$ were present in the mid- and upper levels of the THOM simulation, indicating that THOM-based simulation may generate less cloud ice. According to previous studies [73-75], this is because THOM did not implement the cloud ice formulation scheme from Meyers et al. [73] and thus resulted in producing less cloud ice contents than MORR although both MORR and THOM employed the ice nucleation approach of Cooper [76] and freeze cloud liquid water into cloud ice from Bigg [77]. In addition, the assumed ice nuclei number concentrations of WSM6 and GSFC 
usually decreased with the increase of altitude at the vertical direction; that is, more (less) ice can be produced at lower (higher) altitudes from WSM6 and GSFC schemes than those from NSSL and MORR schemes [75, 78].

For snow, in the THOM simulations, aggressive snow content of $>0.4 \mathrm{~g} \mathrm{~m}^{-3}$ extended more than $200 \mathrm{~km}$ at 5$14 \mathrm{~km}$ altitudes in the convective region (Figure 6(c)). For the THOM MPS, the unique snow PSD assumptions were used, which mainly constrained by in situ measurements under winter storm conditions, leading to smaller particle sizes, and the using mass-diameter relationship mainly resulted from the fractal-like assumption of snow aggregates. Field et al. [61] indicated that these assumptions in THOM might be particularly representative for wintertime precipitation systems rather than typhoons. Instead, the simulated snow content of WSM6 was relatively lower than other four MPSs, possibly because the WSM6 employed a temperature-dependent form and a sink to graupel based on a tunable critical value, causing the discrepancies in snow microphysical processes.

A less compact region of graupel content of $0.05-0.3 \mathrm{~g} \mathrm{~m}^{-3}$ was presented in the simulation using the NSSL MPS (Figure 6(e)), while overwhelming values of graupel $\left(0.05-0.6 \mathrm{~g} \mathrm{~m}^{-3}\right)$ are presented from 5 to $>15 \mathrm{~km}$ in the GSFC simulation. The graupel contents of MORR and WSM6 were also apparently greater than those of the NSSL (Figures 6(a) and 6(d)). A possible explanation is that the NSSL scheme's propensity for graupel allowed graupel particles to range from frozen drops to low-density graupel $\left(300-900 \mathrm{~kg} \mathrm{~m}^{-3}\right)$, whereas the graupel particle densities in all of the WSM6, GSFC, and MORR MPSs were assumed to be constant (Table 1), leading to a disparity in the graupel falling velocity. In addition, the terminal velocity of graupel plays a large part in this sensitivity within tropical cyclone simulation [5], which may also account for the different evolutions of graupel fields. Moreover, graupel stayed at a conspicuous lowest content of $\sim 0.05-0.2 \mathrm{~g} \mathrm{~m}^{-3}$ in the THOM simulation. Note that NSSL produced negligible hail at about $6 \mathrm{~km}\left(\sim 0.01 \mathrm{~g} \mathrm{~m}^{-3}\right)$, and the hail generation occurred only with wet graupel, so that the hail was not merely dominated by high-density ice.

Furthermore, regional average results (Figure S2) show that, above the melting layer (around $5 \mathrm{~km}$ ), the total cloud hydrometeor profiles showed more pronounced sensitivity to different MPSs, which are also suggested by Rajeevan et al. [79] and Wheatley et al. [16].

4.2. Radiance-Based Approach. To further examine the suitability of MPSs in simulating various typhoon hydrometeors, the nonlinear LK-OF approach was applied to radiance indices of SI and EI from the observations and simulations (Figures 7 and 8) as the radiance-based evaluation on liquid and frozen hydrometeors, respectively. Their corresponding statistics are summarized in Table 4.

In terms of EI (Figure 7), the typhoon cloud rain coverage ratio of $78.5 \%$ in NSSL, higher than MORR (75.6\%), WSM6 (54.8\%), GSFC (54.9\%), and THOM (68.4\%), is the closest to the observed value (85.5\%). Moreover, for all five
MPSs, the EI spatial distribution was simulated slightly southwest (Figures 7(a)-7(e), the overlaid OF field). With regard to intensity, the simulated EI was generally lower in the outer spiral rainbands and of greater magnitude in the near-core region than observed EI.

The frequency distributions of the three components of error further demonstrate the difference between simulations and observations. Intensity errors (Figure 7(l)) clearly illustrate that the simulated EI was commonly lower than the observed values, with the same positive mode in all MPSs (Table 4). This result is mainly associated with the underestimation of the high EI areas over the main part of the typhoon, especially for the western area of the exterior spiral cloud band. The GSFC had the minimum average error of 0.05 , while THOM, MORR, and NSSL had the maximum of 0.09. The histogram of the EI displacement errors (Figure $7(\mathrm{~m})$ ) demonstrates that the typical displacement error was about $10 \sim 20 \mathrm{~km}$, where the largest displacement errors occurred in the boundary of the exterior spiral cloud band (Figures S3(k)-S3(o) in SM). In terms of angle error, the five schemes also had similar modes in the histogram (Figure $7(n)$ ) where all are in the first quadrant (corresponding to the southwest bias of the spatial pattern of the angle errors) ranging from $30^{\circ}$ to $60^{\circ}$. In general, these similar systematic biases of EI indicate that all five MPSs underestimated liquid hydrometeors.

With regard to SI (Figure 8), one of the most obvious features is that the simulated SI intensity over the southwest part of the typhoon was significantly higher than the observed intensity, which resulted in the corresponding negative average intensity error, though a slightly positive bias is on the outer cloud edge of the western part of the typhoon (Figures 8(f)-8(j)). Among five MPSs, the NSSL has the smallest mean intensity error of -0.03 , while THOM has the largest value of -0.20 . In addition, it can be noted that the displacement and directional errors of the various schemes were similar, about $10 \sim 20 \mathrm{~km}$ to the southwest $\left(\sim 45^{\circ}\right)$ of the observations, which is also consistent with the displacement and direction error of EI. These errors may be caused by a model system issue, such as imperfectly balanced initial and boundary conditions or a deficiency in the other models' physical processes, with the placement of the typhoon.

In order to understand the assignment between liquid and frozen precipitation hydrometeors in typhoon, the joint histograms of SI versus EI were calculated, as shown in Figure 9. Overall, the EI values increased with increasing SI from observations (Figure 9(a)), which implies the fact that liquid hydrometeor would increase with frozen hydrometeors such as graupel and snow in actual typhoons. However, the results from the five MPSs generally disagreed with the observed trends, showing that a slow increase of EI as the SI increased (Figures 9(b) and 9(c)). It indicates that there is a problem in the simultaneous growth process of the simulated frozen and liquid hydrometeors. On the contrary, the observed mode was bounded with the SI values $0.8 \sim 0.9$, while the simulated mode extended to higher SI and EI, especially for WSM6, GSFC, and MORR with SI values 1.5. For a given EI value, moreover, the simulated SI value was generally 0.5 greater than the observations. This feature is 


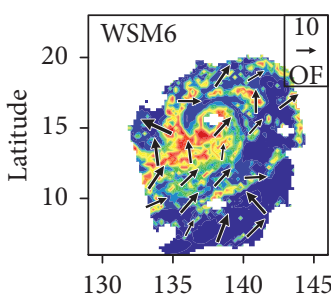

(a)

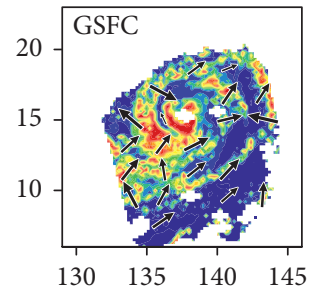

(b)

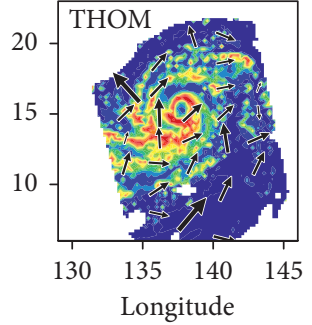

(c)

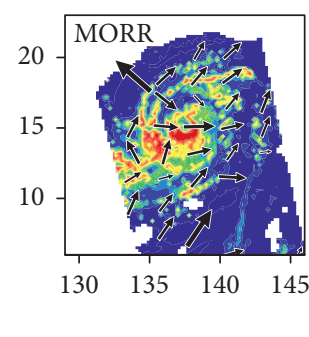

(d)

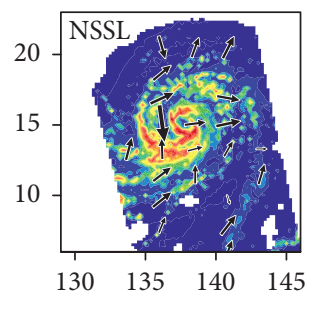

(e)
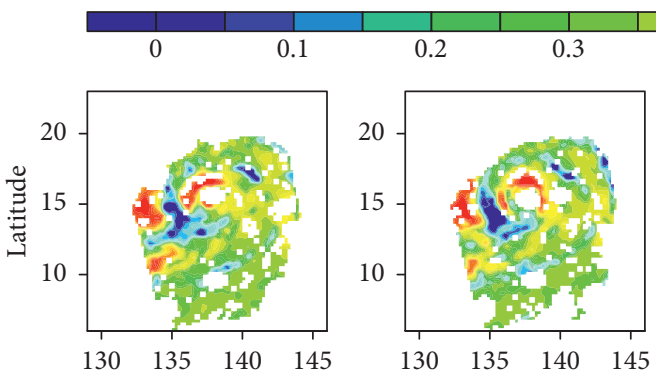

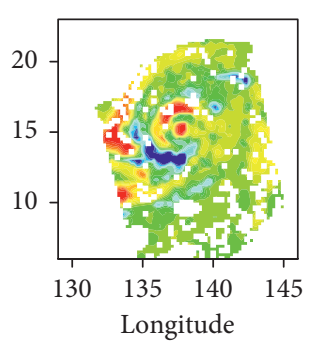

(h)

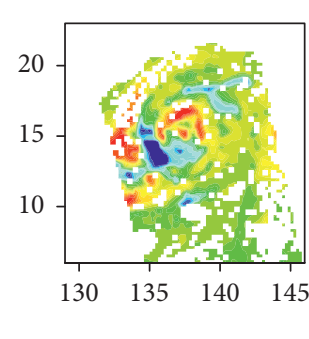

(i)

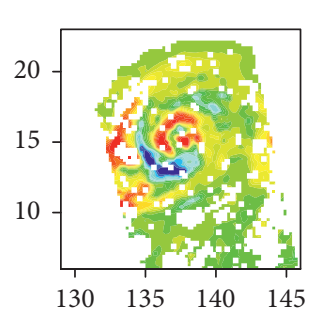

(g)

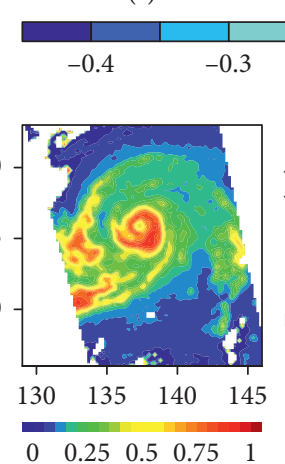

(k)

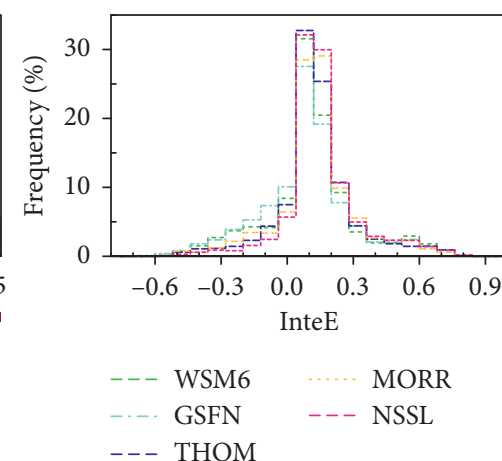

(1)

\begin{tabular}{l|l|l|l|l|l|l|}
\hline & & & & & $\mid$ \\
0.1 & 0.2 & 0.3 & 0.4
\end{tabular}

(j)

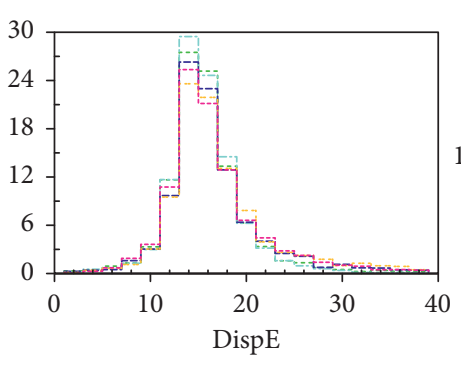

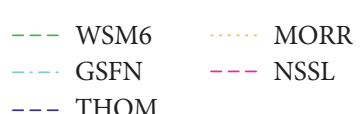

(m)

(n)

Figure 7: The OF field and the three components of error in the five simulated fields for the EI index. (a) (e) The spatial distribution of the emission index (EI) field: (a) WSM6, (b) GSFC, (c) THOM, (d) MORR, and (e) NSSL; the overlaid OF field (arrows) mapping the simulated to $(k)$ the observed EI field. The spatial distribution of intensity error (f) WSM6, (g) GSFC, (h) THOM, (i) MORR, and (j) NSSL and histogram of the three components of the simulation error of (l) intensity error (InteE), (m) displacement error (DispE), and (n) angular error. See text for details.

likely related to the larger amount of frozen precipitation hydrometeors in modeling, especially for large frozen hydrometeor of graupel as the main contributor to SI (Figures 5 and 6; Tables 3 and S4).

In general, the results from NSSL were closer to the observations than those from the other schemes at the SI extension, consistent with the less graupel in NSSL mentioned in Tables 3 and S4. Moreover, the EI values with high occurrence frequency in all five schemes were appreciably (> 0.15) lower than the observations of MWRI, suggesting that the simulated liquid hydrometeors were less than the actuals, especially for rainwater having strong emission effect. In addition, the high-value region in simulated joint probability density distribution is more inclined to the SI axis, whereas the observational results tend to the EI axis, suggesting large uncertainties of MPSs in the matching ratio of the simulated frozen-liquid hydrometeors. Even so, it is distinct that the NSSL reproduced a more realistic hydrometeor distribution than did the other four schemes.

\section{Discussion}

To illustrate the contribution of the specific hydrometeor to the radiance indices, the sensitivity was determined by comparing the difference of calculated SI and EI between all with and without this hydrometeor. Note that a hydrometeor species was removed only in the radiative transfer calculations and not in the actual simulations. This sensitivity experiments will show the impact of each hydrometeor species on the simulation-derived radiance indices and will 


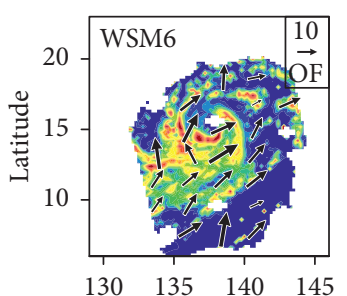

(a)

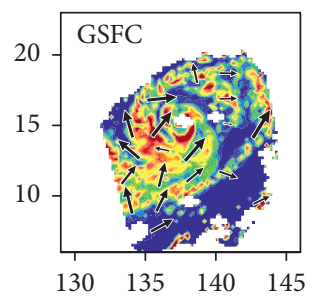

(b)

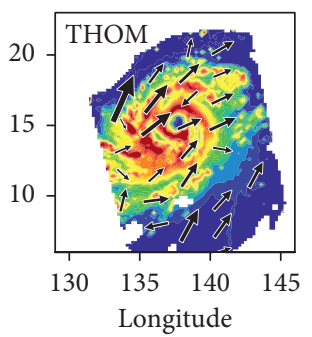

(c)

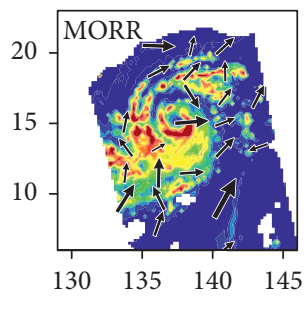

(d)

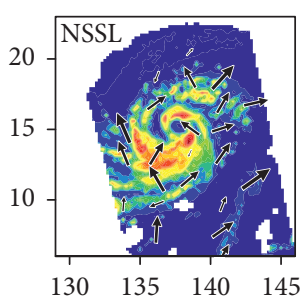

(e)
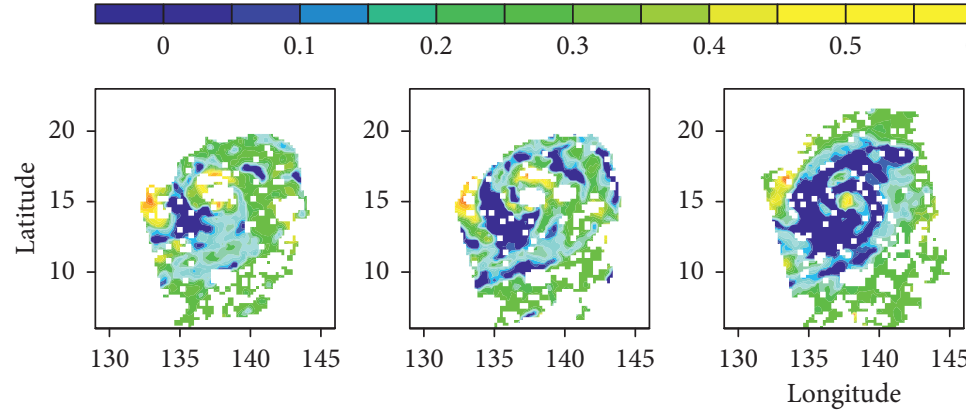

(h)

(g)

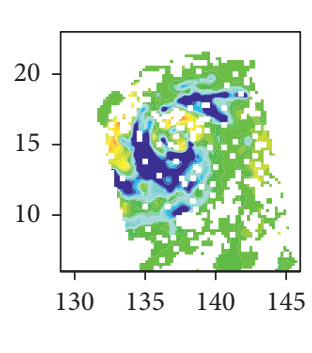

(i)

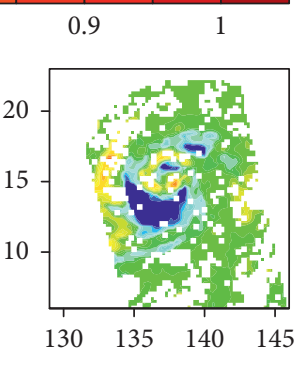

(f)

\begin{tabular}{|c|c|c|c|c|c|c|c|c|c|c|}
\hline 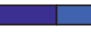 & 1 & 1 & $I$ & $I$ & 1 & $I$ & $I$ & $I$ & $I$ & \\
\hline-0.4 & -0.3 & -0.2 & -0.1 & 0 & 0.1 & 0.2 & 0.3 & 0.4 & 0.5 & 0.6 \\
\hline
\end{tabular}

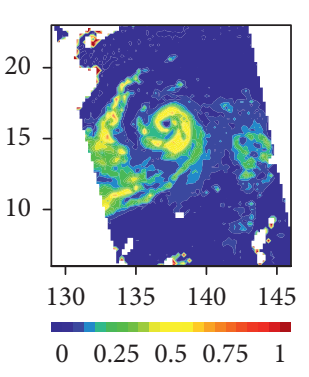

(k)

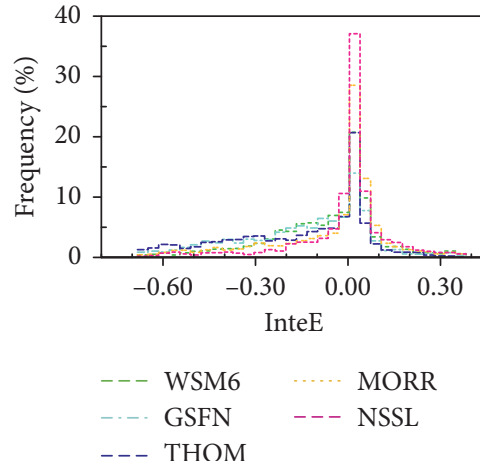

(l)
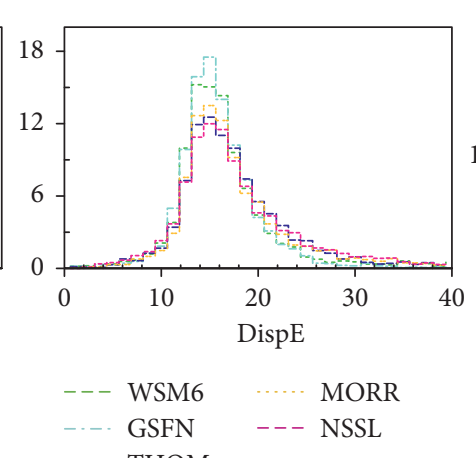

-.. THOM

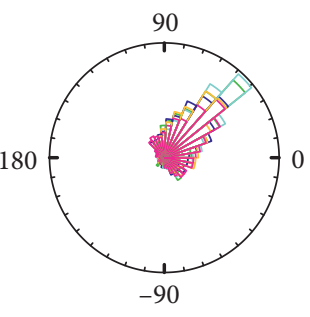

(m) (n)

Figure 8: As in Figure 7, except for the scattering index (SI).

Table 4: Three error component statistics of the OF field.

\begin{tabular}{|c|c|c|c|c|c|c|c|c|c|c|c|}
\hline \multirow{2}{*}{ Metric } & \multirow{2}{*}{ Average } & \multicolumn{5}{|c|}{ Emission index (EI) } & \multicolumn{5}{|c|}{ Scattering index (SI) } \\
\hline & & WSM6 & GSFC & THOM & MORR & NSSL & WSM6 & GSFC & THOM & MORR & NSSL \\
\hline \multirow{2}{*}{ Intensity error (unitless) } & Mode & 0.04 & 0.04 & 0.04 & 0.12 & 0.04 & 0.00 & 0.00 & 0.00 & 0.00 & 0.00 \\
\hline & Mean & 0.07 & 0.05 & 0.09 & 0.09 & 0.09 & -0.08 & -0.17 & -0.20 & -0.08 & -0.03 \\
\hline \multirow{2}{*}{ Displacement error $(\mathrm{km})$} & Mode & 13.0 & 13.0 & 13.0 & 13.0 & 13.0 & 13.1 & 14.4 & 14.4 & 14.4 & 14.4 \\
\hline & Mean & 15.3 & 14.8 & 17.2 & 17.7 & 16.3 & 17.0 & 15.6 & 20.7 & 21.0 & 20.0 \\
\hline \multirow{2}{*}{ Angular error $\left({ }^{\circ}\right)$} & Mode & 45.0 & 45.0 & 45.0 & 45.0 & 45.0 & 45.0 & 45.0 & 45.0 & 45.0 & 45.0 \\
\hline & Mean & 36.1 & 32.6 & 30.6 & 30.3 & 32.9 & 32.5 & 30.9 & 34.0 & 32.0 & 31.1 \\
\hline
\end{tabular}

Mode and mean are two kinds of metrics for "averages."

enable us to visually and accurately evaluate the deviation contribution of various hydrometeor species in different MPSs.

Taking the stronger stage of typhoon Neoguri on 05/07/ 2014 as the same example as previous work, the results of the sensitivity experiment were given in Figure 10. It is clear that cloud ice has negligible impact on SI, while graupel and snow have appreciable impacts on it. When snow is removed, the maximum value of SI in the joint histograms of NSSL and THOM (Figure 10(o)(z1)) decreases below 0.9, which is slightly smaller the observed SI value, but the SI ranges of the other schemes $(\mathrm{SI}>1.2)$ are still obviously greater than the observed values, especially for MORR and GSFC. Note that calculations with no snow separated out the effect of graupel 

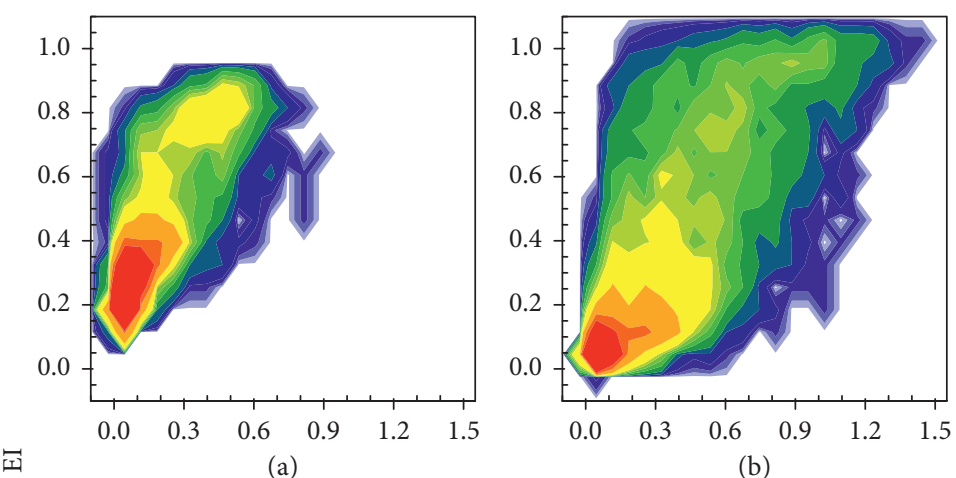

(b)

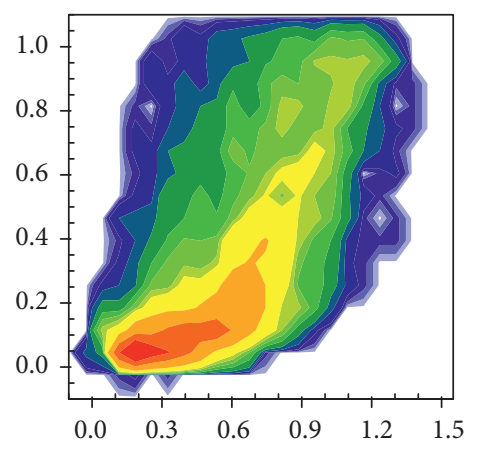

(d)

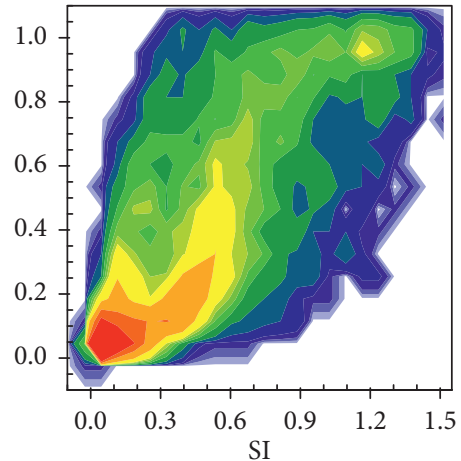

(e)

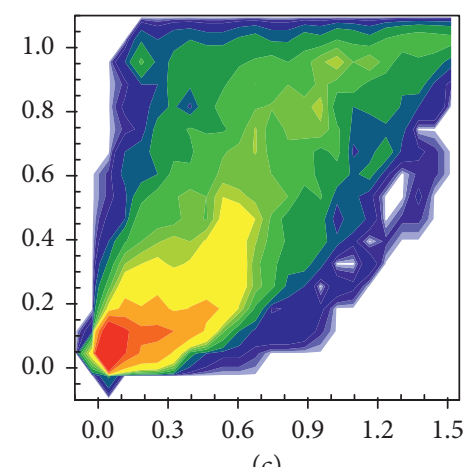

(c)

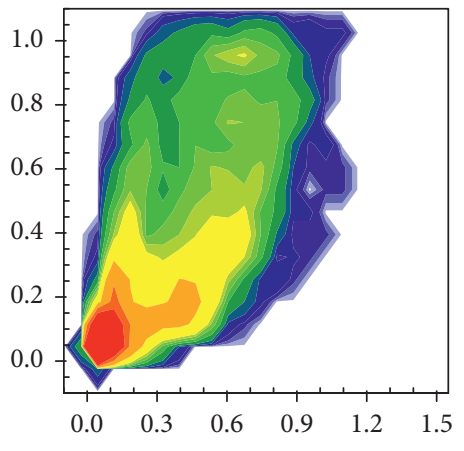

(f)

\begin{tabular}{|l|l|l|l|l|l|l|l|l|}
\hline & & & & & & & \\
\hline
\end{tabular}

Figure 9: Joint histograms of scattering index (SI) and emission index (EI) for (a) FY-3B-MWRI and five simulations (b-f), (b) WSM6, (c) GSFC, (d) THOM, (e) MORR, and (f) NSSL, corresponding to the time of FY-3B overpasses of $0705 \mathrm{~A}$.

in SI, showing that the graupel contents derived from the WSM6, GSFC, and MORR were greatly exaggerated. In addition, SI seems to be somewhat affected by snow. When graupel is removed, the SI extensions of all the schemes are still larger than the observed SI value, indicating that the simulated snow contents are exaggerated (Figure 10).

For all five MPSs, the simulated joint histograms show that cloud water had a negligible impact on EI, which indicates that EI is mainly affected by the emission of rainwater as mentioned above. In this case with the absence of cloud water, the maximum value range of EI was still slightly higher than the observed value, but the EI value at the maximum probability was lower than the observed value, indicating that the five schemes somewhat overestimated strong rainwater (such as in the near-core region and in strong convective activity areas), while it is possible to underestimate the content of moderate rainwater (in the less active outer spiral rainbands). In addition, supercooled water and graupel have competing effects on the upwelling brightness temperature. While graupel reduces the brightness temperature by scattering upwelling radiation, emissions from supercooled water droplets increase the brightness temperature $[71,80,81]$. Thus, supercooled water masks the scattering signal that results from graupel at the same vertical level. Hong et al. [82] pointed out that the channels at $89 \mathrm{GHz}$ are strongly positive (increasing the brightness temperature, that is, decreasing SI), sensitive to variations in the liquid water content above $5 \mathrm{~km}$ (supercooled water). The calculations with no cloud water had little impact on SI for WSM6, GSFC, THOM, and MORR, indicating that there was too little supercooled water in the above four schemes, so that SI was not significantly decreased. Therefore, too little supercooled water may be another reason why the SI extensions of these four schemes were greater than the observed counterparts. However, the spread in the NSSL joint histograms with no cloud water (Figure $10(\mathrm{z} 3))$ is more expansive $(\sim 0.3)$ along the SI-axis than that with cloud water (Figure $10(\mathrm{y})$ ). This indicates that NSSL, to some extent, could truly generate larger cloud water content and a deep layer of supercooled water extending up to about $11 \mathrm{~km}$ (as shown in Figures 6 and S2 in SM), consistent with the results of Cecil and Zipser [71] and Reinhart et al. [72].

Note that the tropical cyclone first and foremost is generated by the complex interactions of the large-scale dynamics and cumulus convection [83-85]. To date, a successful forecast of the tropical cyclones strongly depends on how successfully a model can represent the aspects related to these interaction processes. However, the selection of appropriate MPSs responsible for hydrometeor variations makes a difference as well for the accurate simulation of tropical cyclone. Actually, it has been well established that 


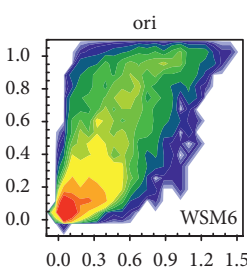

(a)

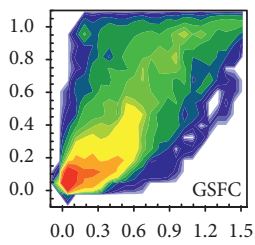

(g)

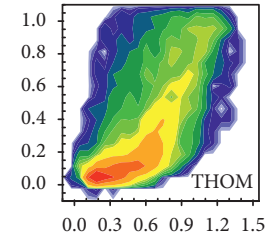

(m)

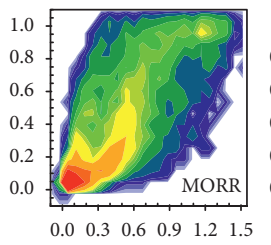

(s)

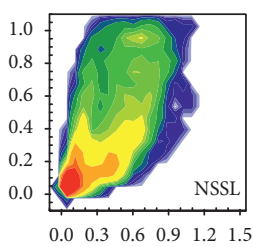

(y)

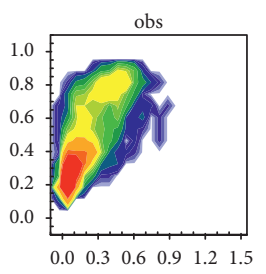

(z5)

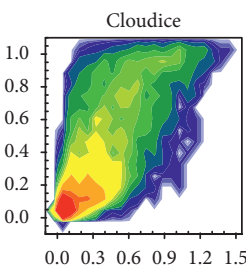

(b)

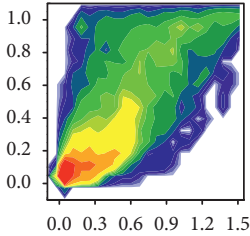

(h)

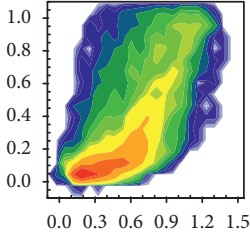

(n)

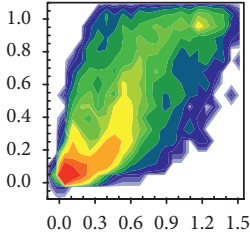

(t)

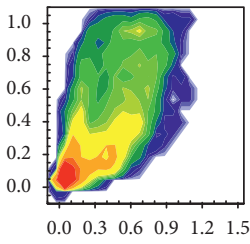

(z)

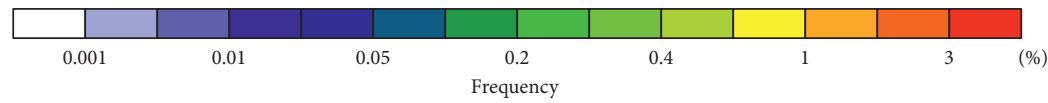

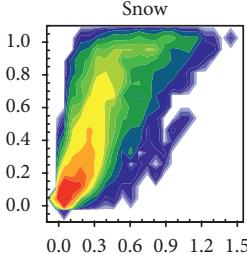

(c)

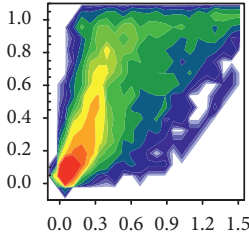

(i)

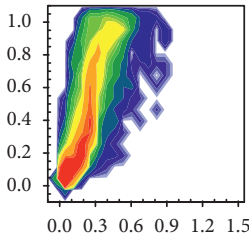

(o)

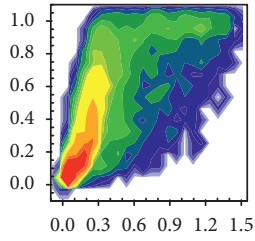

(u)

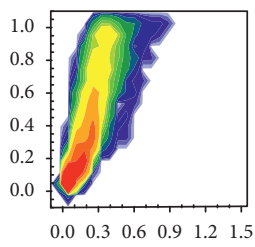

(z1)

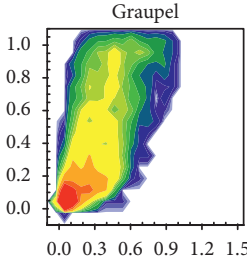

(d)

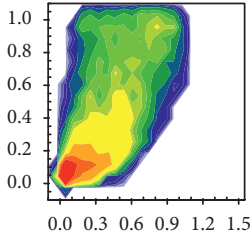

(j)

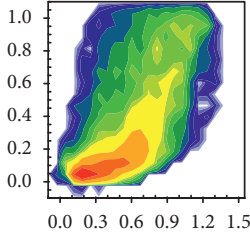

(p)

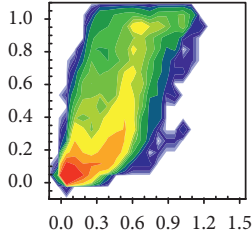

(v)

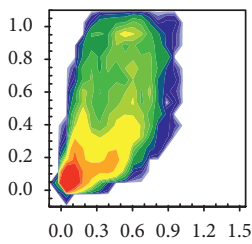

(z2)

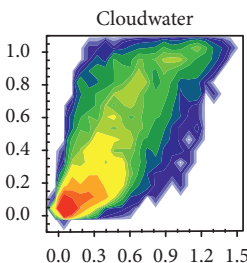

(e)

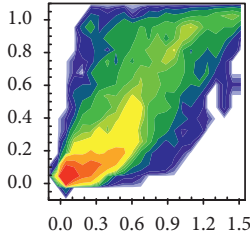

(k)

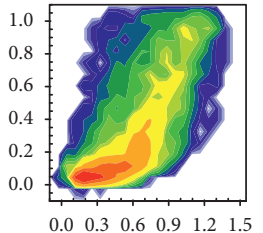

(q)

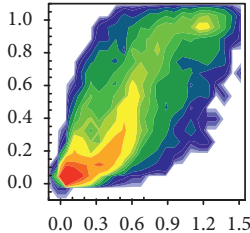

(w)

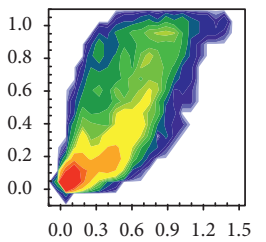

(z3)

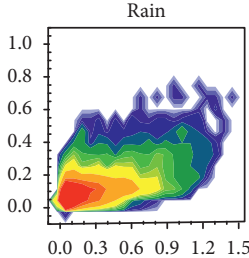

(f)

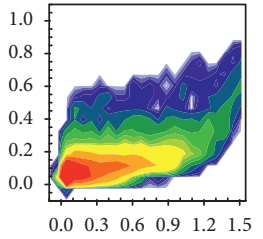

(l)

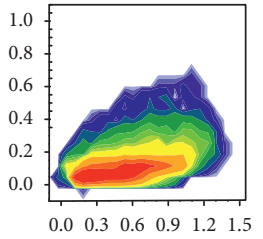

(r)

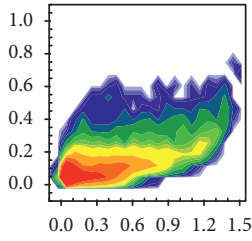

(x)

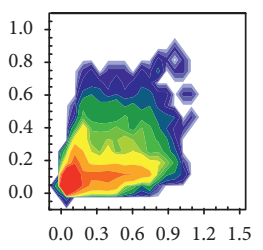

$(\mathrm{z} 4)$

FIGURE 10: Joint histograms of the scattering index (SI) and the emission index (EI) for sensitivity tests of computing the SI and EI with all but one hydrometeor species present and comparing those with the experiment that used all of the hydrometeor species, $0705 \mathrm{~A}$ for instance, within a radius of $400 \mathrm{~km}$ from the cyclone center, from top row to bottom row WSM6 (first row), GSFC (second row), THOM (third row), MORR (fourth row), NSSL (fifth row), and observed (z5). The first column is the control run using all hydrometeor species. The other columns represent the calculations without the indicated hydrometeor species (cloud ice (second column)), snow (third column), graupel (fourth column), cloud water (fifth column), and rain (sixth column).

the released latent heat (convective heating) caused by phase transition of cloud hydrometeors is the main source of energy in tropical cyclone [86], and different types of hydrometeors lead to quite different structures and intensities of tropical cyclones through their interactions with radiation $[8,87,88]$. As shown here, even with the same dynamical framework and other physics schemes, the simulations using NSSL as the representative of the double-moment MPS are much closer to the observations than other MPSs, in term of both hydrometeor distributions and typhoon intensity variations. This should not be regarded as coincidence since the generated hydrometeors in the cloud microphysics process would exert influences on typhoon intensity that is related to dynamics through changing latent heat and radiation. 


\section{Conclusions}

In this study, based on a case of typhoon Neoguri, the ability of typhoon hydrometeor simulation about five MPSs in the WRF Version 3.6 model, including GSFC, WSM6, THOM, MORR, and NSSL, was directly and indirectly evaluated through comparing with observations from FY-3B satellite. The following conclusions can be drawn:

(1) Comparison with JTWC reports indicates that the simulated track is not very sensitive to the chosen MPSs. Among these schemes, the MORR produces a minimal average track error of $69.5 \mathrm{~km}$. Moreover, NSSL tends to reproduce more actually intensity variations in the whole typhoon life cycle. On the contrary, the simulated typhoon surface precipitation exhibits systematically wetter conditions over the strong convective activity areas of the inner rainband, whereas it exhibits noticeably drier conditions for the stratiform cloud rainband. In comparison, the surface precipitation pattern of NSSL is closer to the observed pattern.

(2) In terms of satellite retrieval-based evaluation, simulated IWPs by all MPSs are higher than retrievals in most areas. Notably, the spatial pattern of IWP for NSSL and WSM6 is generally closer to those from FY-3B observations. Specially, within the $1^{\circ}$ radius inner-core zone and $2.5^{\circ} \sim 4^{\circ}$ outside-annular zones, the IWPs derived from NSSL with less graupel are closer to the retrieved IWP. On the contrary, over almost all areas, THOM produces the largest amount of IWPs, which are mainly in the form of snow.

(3) For the radiance-based evaluation, the horizontal distributions of simulated EI and SI were statistically verified using the nonlinear LK-OF approach. The results show that both the simulated EI and SI had significant intensity bias, especially in strong convective areas. This implies that the simulated liquid hydrometeor is generally lower in the outer spiral rainbands than the one as observed from satellite. However, the simulated frozen precipitation hydrometeor is obviously greater over the southwest part of the typhoon. In addition, similar displacement and angular errors (a systematic southwest bias of approximately about $10 \sim 20 \mathrm{~km}$ ) of EI or SI among the five MPSs might indicate a serious model system issue.

(4) The SI-EI joint histograms show that NSSL reproduces a more realistic matching proportion of frozen and liquid hydrometeors than any of the other four schemes, especially for supercooled cloud water.

Overall, for this case of Neoguri, the double-moment MPS of NSSL, allowing for greater flexibility in the size distribution and the density of graupel particles with more complex microphysical processes, could offer more reliable representations for the simulation of hydrometeors, as well as the evolution of typhoon.

In summary, our work advances our understanding of the performance of various MPSs of cloud in simulating the hydrometeors of tropical cyclones. Admittedly, the heightrevolved structures of hydrometeors are not evaluated at all, which merits further investigation in the future by combining passive and active satellite observations, including CALIPSO, Cloudsat, TRMM, and GPM [89, 90].

\section{Data Availability}

The MWRI data were provided by FENGYUN Satellite Data Center from http://data.nsmc.org.cn/portalsite/default.aspx. The JTWC data were downloaded from https://www.usno. navy.mil/NOOC/nmfc-ph/RSS/jtwc/best_tracks/. The National Center for Atmospheric Research's Mesoscale and Microscale Meteorology Division provided the WRF model available at http://www2.mmm.ucar.edu/wrf/users/. The MWRT model was accessed from http://cirrus.met.fsu.edu/ research/mwrt.html. All data used to support the findings of this study are available from the corresponding author upon request.

\section{Conflicts of Interest}

The authors declare that they have no conflicts of interest.

\section{Acknowledgments}

The authors would like to thank Dr. Ted Mansell at the National Severe Storms Laboratory for his great help on understanding the NSSL scheme in the WRF. FY-3B data were obtained from FENGYUN Satellite Data Center. This work was supported by the Ministry of Science and Technology of China (grant nos. 2018YFC1507401 and 2017YFC1501402), the National Natural Science Foundation of China (grant nos. 41875024, 41830104, and 41375030), and the Fundamental Research Funds for the Central Universities. This work was also sponsored by the Jiangsu Provincial 2011 program (Collaborative Innovation Center of Climate Change).

\section{Supplementary Materials}

Table S1: eight orbit datasets of FY-3B, which were obtained from the FY-3B-MWRI 83 overpass during the different stages of typhoon Neoguri's life cycle. Table S2: statistics of typhoons translational speed for the model simulations and the best track (JTWC), during 0000 UTC 3 July to 0000 UTC 10 July 2014 at $6 \mathrm{~h}$ intervals. Table S3: validation statistics between simulated tracks and best track (JTWC). Table S4: statistics of the domain-averaged hydrometeor path $(\mathrm{g} / \mathrm{m} 2)$ of cloud water $(\mathrm{Cw})$, cloud ice $(\mathrm{Ci})$, rain water $(\mathrm{Ra})$, snow $(\mathrm{Sn})$, graupel $(\mathrm{Gr})$, and hail (Ha), based on matched instances of 0705A, which are derived from five MPSs. Total is total vertically integrated hydrometeor paths. Figure S1: horizontal distribution of model-simulated graupel hydrometeor path $(\mathrm{g} / \mathrm{m} 2)$ produced with the super typhoon Neoguri, using the MPSs of WSM6 (first column), GSFC (second column), THOM (third column), MORR (fourth column), and NSSL (fifth column). Note that the first to fourth rows correspond to the time of FY-3B overpasses of 0703D, 0705A, 0707A, and 0708D. Figure S2: domain- 
averaged vertical profile of hydrometeor content $(\mathrm{g} / \mathrm{m} 3)$ for the simulations matched $0705 \mathrm{~A}$ scene captured by FY-3B over domains within a radius of $400 \mathrm{~km}$ from the cyclone center (the typhoon's surface minimum pressure), for (a) cloud ice content, (b) snow water content, (c) graupel water content, (d) cloud water content, and (e) rain water content, respectively. Figure S3: the OF field and the three components of error in the five simulated fields. (a) (e) The spatial distribution of the emission index (EI) field: (a) WSM6, (b) GSFC, (c) THOM, (d) MORR, and (e) NSSL; the overlaid OF field (arrows) mapping the simulated to the observed SI field (u). The spatial distribution of intensity error (f) WSM6, (g) GSFC, (h) THOM, (i) MORR, and (j) NSSL; the spatial distribution of displacement error (k) WSM6, (l) GSFC, (m) THOM, (n) MORR, and (o) NSSL; the spatial distribution of angular error (p) WSM6, (q) GSFC, (r) THOM, (s) MORR, and $(\mathrm{t})$ NSSL; and histogram of the three components of the simulation error of (v) intensity error (AA), (w) displacement error (DispE), and (x) angular error (see text for details of Figure S4. As in Figure S3, but for the scattering index (SI)). (Supplementary Materials)

\section{References}

[1] S. Pattnaik, C. Inglish, and T. N. Krishnamurti, "Influence of rain-rate initialization, cloud microphysics, and cloud torques on hurricane intensity," Monthly Weather Review, vol. 139, no. 2, pp. 627-649, 2011.

[2] R. Rogers, "Convective-scale structure and evolution during a high-resolution simulation of tropical cyclone rapid intensification," Journal of the Atmospheric Sciences, vol. 67, no. 1 , pp. 44-70, 2010.

[3] J. L. Vigh and W. H. Schubert, "Rapid development of the tropical cyclone warm core," Journal of the Atmospheric Sciences, vol. 66, no. 11, pp. 3335-3350, 2009.

[4] T. Zhu and D.-L. Zhang, "Numerical simulation of Hurricane Bonnie (1998). Part II: sensitivity to varying cloud microphysical processes," Journal of the Atmospheric Sciences, vol. 63, no. 1, pp. 109-126, 2006.

[5] C. N. Franklin, G. J. Holland, and P. T. May, "Sensitivity of tropical cyclone rainbands to ice-phase microphysics," Monthly Weather Review, vol. 133, no. 8, pp. 2473-2493, 2005.

[6] S. J. Lord, H. E. Willoughby, and J. M. Piotrowicz, "Role of a parameterized ice-phase microphysics in an axisymmetric, nonhydrostatic tropical cyclone model," Journal of the Atmospheric Sciences, vol. 41, no. 19, pp. 2836-2848, 1984.

[7] H. E. Willoughby, H.-L. Jin, S. J. Lord, and J. M. Piotrowicz, "Hurricane structure and evolution as simulated by an axisymmetric, nonhydrostatic numerical model," Journal of the Atmospheric Sciences, vol. 41, no. 7, pp. 1169-1186, 1984.

[8] Y. Piotrowicz, "An explicit simulation of tropical cyclones with a triply nested movable mesh primitive equation model: TCM3. Part II: model refinements and sensitivity to cloud microphysics parameterization," Monthly Weather Review, vol. 130, no. 12, pp. 3022-3036, 2002.

[9] Z. Pu, X. Li, C. S. Velden, S. D. Aberson, and W. T. Liu, "The impact of aircraft dropsonde and satellite wind data on numerical simulations of two landfalling tropical storms during the tropical cloud systems and processes experiment," Weather and Forecasting, vol. 23, no. 1, pp. 62-79, 2008.

[10] J. Li, G. Wang, W. Lin, Q. He, Y. Feng, and J. Mao, "Cloudscale simulation study of Typhoon Hagupit (2008) Part I: microphysical processes of the inner core and three-dimensional structure of the latent heat budget," Atmospheric Research, vol. 120-121, pp. 170-180, 2013.

[11] W.-K. Tao, J. J. Shi, S. S. Chen et al., "The impact of microphysical schemes on hurricane intensity and track," AsiaPacific Journal of Atmospheric Sciences, vol. 47, no. 1, pp. 1-16, 2011.

[12] I. Pytharoulis, S. Kartsios, I. Tegoulias et al., "Sensitivity of a mediterranean tropical-like cyclone to physical parameterizations," Atmosphere, vol. 9, no. 11, p. 436, 2018.

[13] W. C. Skamarock, J. B. Klemp, J. Dudhia et al., “A Description of the Advanced Research WRF Version 3. NCAR Technical Note," NCAR/TN-475+STR, Mesoscale and Microscale Meteorology Division, National Center for Atmospheric Research, Boulder, CO, USA, 2008.

[14] A. L. Molthan and B. A. Colle, "Comparisons of single- and double-moment microphysics schemes in the simulation of a synoptic-scale snowfall event," Monthly Weather Review, vol. 140, no. 9, pp. 2982-3002, 2012.

[15] W. Roh, M. Satoh, and T. Nasuno, "Improvement of a cloud microphysics scheme for a global nonhydrostatic model using TRMM and a satellite simulator," Journal of the Atmospheric Sciences, vol. 74, no. 1, pp. 167-184, 2017.

[16] D. M. Wheatley, N. Yussouf, and D. J. Stensrud, "Ensemble Kalman filter analyses and forecasts of a severe mesoscale convective system using different choices of microphysics schemes," Monthly Weather Review, vol. 142, no. 9, pp. 3243-3263, 2014.

[17] E.-K. Seo and M. I. Biggerstaff, "Impact of cloud model microphysics on passive microwave retrievals of cloud properties. Part II: uncertainty in rain, hydrometeor structure, and latent heating retrievals," Journal of Applied Meteorology and Climatology, vol. 45, no. 7, pp. 955-972, 2006.

[18] K. Van Weverberg, A. M. Vogelmann, W. Lin et al., "The role of cloud microphysics parameterization in the simulation of mesoscale convective system clouds and precipitation in the tropical western Pacific," Journal of the Atmospheric Sciences, vol. 70, no. 4, pp. 1104-1128, 2013.

[19] G. M. McFarquhar, H. Zhang, G. Heymsfield et al., "Factors affecting the evolution of Hurricane Erin (2001) and the distributions of hydrometeors: role of microphysical processes," Journal of the Atmospheric Sciences, vol. 63, no. 1, pp. 127-150, 2006.

[20] D. E. Waliser, J. L. F. Li, C. P. Woods et al., "Cloud ice: a climate model challenge with signs and expectations of progress," Journal of Geophysical Research: Atmospheres, vol. 114, no. D8, 2009.

[21] V. S. Galligani, D. Wang, M. Alvarez Imaz, P. Salio, and C. Prigent, "Analysis and evaluation of WRF microphysical schemes for deep moist convection over south-eastern South America (SESA) using microwave satellite observations and radiative transfer simulations," Atmospheric Measurement Techniques, vol. 10, no. 10, pp. 3627-3649, 2017.

[22] S. B. Sieron, E. E. Clothiaux, F. Zhang, Y. Lu, and J. A. Otkin, "Comparison of using distribution-specific versus effective radius methods for hydrometeor single-scattering properties for all-sky microwave satellite radiance simulations with different microphysics parameterization schemes," Journal of Geophysical Research: Atmospheres, vol. 122, no. 13, pp. 7027-7046, 2017.

[23] F. Chevallier and P. Bauer, "Model rain and clouds over oceans: comparison with SSM/I observations," Monthly Weather Review, vol. 131, no. 7, pp. 1240-1255, 2003.

[24] F. Yun-Fei, H. Zhi-Wei, L. Tian-Yi, S. Zhong-Ping, and W. Yu, "Evaluation of WRF model hydrometeors based on 
TMI observations using an indirect method," Atmospheric and Oceanic Science Letters, vol. 5, no. 1, pp. 32-37, 2012.

[25] M. Han, S. A. Braun, W. S. Olson, P. O. G. Persson, and J.-W. Bao, "Application of TRMM PR and TMI measurements to assess cloud microphysical schemes in the MM5 for a winter storm," Journal of Applied Meteorology and Climatology, vol. 49, no. 6, pp. 1129-1148, 2010.

[26] M. Han, S. A. Braun, T. Matsui, and T. Iguchi, "Comparisons of bin and bulk microphysics schemes in simulations of topographic winter precipitation with radar and radiometer measurements," Quarterly Journal of the Royal Meteorological Society, vol. 144, no. 715, pp. 1926-1946, 2018.

[27] T. Iguchi, J. Santanello, J. J. Shi et al., "Introducing multisensor satellite radiance-based evaluation for regional Earth System modeling," Journal of Geophysical Research: Atmospheres, vol. 119, no. 13, pp. 8450-8475, 2014.

[28] X. Li, W.-K. Tao, T. Matsui et al., "Improving a spectral bin microphysical scheme using TRMM satellite observations," Quarterly Journal of the Royal Meteorological Society, vol. 136, no. 647, pp. 382-399, 2010.

[29] T. Matsui, X. Zeng, W.-K. Tao, H. Masunaga, W. S. Olson, and S. Lang, "Evaluation of long-term cloud-resolving model simulations using satellite radiance observations and multifrequency satellite simulators," Journal of Atmospheric and Oceanic Technology, vol. 26, no. 7, pp. 1261-1274, 2009.

[30] Y. Wang, C. N. Long, L. Leung et al., "Evaluating regional cloud-permitting simulations of the WRF model for the tropical warm pool international cloud experiment (TWPICE), Darwin, 2006," Journal of Geophysical Research: Atmospheres, vol. 114, no. D21, 2009.

[31] J. Yang, P. Zhang, N. Lu, Z. Yang, J. Shi, and C. Dong, "Improvements on global meteorological observations from the current Fengyun 3 satellites and beyond," International Journal of Digital Earth, vol. 5, no. 3, pp. 251-265, 2012.

[32] Z. Yang, N. Lu, J. Shi, P. Zhang, C. Dong, and J. Yang, "Overview of FY-3 payload and ground application system," IEEE Transactions on Geoscience and Remote Sensing, vol. 50, no. 12, pp. 4846-4853, 2012.

[33] Y. Han, X. Zou, and F. Weng, "Cloud and precipitation features of Super Typhoon Neoguri revealed from dual oxygen absorption band sounding instruments on board FengYun3C satellite," Geophysical Research Letters, vol. 42, no. 3, pp. 916-924, 2015.

[34] Y.-A. Liou, J.-C. Liu, C. P. Liu, and C.-C. Liu, "Season-dependent distributions and profiles of seven super-typhoons (2014) in the northwestern pacific ocean from satellite cloud images," IEEE Transactions on Geoscience and Remote Sensing, vol. 56, no. 5, pp. 2949-2957, 2018.

[35] G. Liu, "A fast and accurate model for microwave radiance calculations," Journal of the Meteorological Society of Japan. Ser. II, vol. 76, no. 2, pp. 335-343, 1998.

[36] G. Liu, "Approximation of single scattering properties of ice and snow particles for high microwave frequencies," Journal of the Atmospheric Sciences, vol. 61, no. 20, pp. 2441-2456, 2004.

[37] C. Dong, J. Yang, W. Zhang et al., "An overview of a new Chinese weather satellite FY-3A," Bulletin of the American Meteorological Society, vol. 90, no. 10, pp. 1531-1544, 2009.

[38] H. Yang, F. Weng, L. Lv et al., "The FengYun-3 microwave radiation imager on-orbit verification," IEEE Transactions on Geoscience and Remote Sensing, vol. 49, no. 11, pp. 4552-4560, 2011.

[39] Y. Wang, Y. Fu, X. Fang et al., "Estimating ice water path in tropical cyclones with multispectral microwave data from the
FY-3B satellite," IEEE Transactions on Geoscience and Remote Sensing, vol. 52, no. 9, pp. 5548-5557, 2014.

[40] G. Liu and J. A. Curry, "Retrieval of precipitation from satellite microwave measurement using both emission and scattering," Journal of Geophysical Research: Atmospheres, vol. 97, no. D9, pp. 9959-9974, 1992.

[41] G. Petty, "Physical retrievals of over-ocean rain rate from multichannel microwave imagery. Part I: theoretical characteristics of normalized polarization and scattering indices," Meteorology and Atmospheric Physics, vol. 54, no. 1-4, pp. 79-99, 1994.

[42] G. W. Petty and K. B. Katsaros, "Precipitation observed over the South China Sea by the Nimbus-7 scanning multichannel microwave radiometer during winter MONEX," Journal of Applied Meteorology, vol. 29, no. 4, pp. 273-287, 1990.

[43] G. Liu, J. A. Curry, and R.-S. Sheu, "Classification of clouds over the western equatorial Pacific Ocean using combined infrared and microwave satellite data," Journal of Geophysical Research, vol. 100, no. D7, pp. 13811-13826, 1995.

[44] R. W. Spencer, H. M. Goodman, and R. E. Hood, "Precipitation retrieval over land and ocean with the SSM/I: identification and characteristics of the scattering signal," Journal of Atmospheric and Oceanic Technology, vol. 6, no. 2, pp. 254-273, 1989.

[45] M. J. Iacono, J. S. Delamere, E. J. Mlawer et al., "Radiative forcing by long-lived greenhouse gases: calculations with the AER radiative transfer models," Journal of Geophysical Research: Atmospheres, vol. 113, no. D13, 2008.

[46] P. A. Jiménez, J. Dudhia, J. F. González-Rouco, J. Navarro, J. P. Montávez, and E. García-Bustamante, "A revised scheme for the WRF surface layer formulation," Monthly Weather Review, vol. 140, no. 3, pp. 898-918, 2012.

[47] S.-Y. Hong, Y. Noh, and J. Dudhia, "A new vertical diffusion package with an explicit treatment of entrainment processes," Monthly Weather Review, vol. 134, no. 9, pp. 2318-2341, 2006.

[48] M. Tiedtke, "A comprehensive mass flux scheme for cumulus parameterization in large-scale models," Monthly Weather Review, vol. 117, no. 8, pp. 1779-1800, 1989.

[49] C. Zhang, Y. Wang, and K. Hamilton, "Improved representation of boundary layer clouds over the southeast pacific in ARW-WRF using a modified Tiedtke cumulus parameterization scheme," Monthly Weather Review, vol. 139, no. 11, pp. 3489-3513, 2011.

[50] J. Molinari and M. Dudek, "Parameterization of convective precipitation in mesoscale numerical models: a critical review," Monthly Weather Review, vol. 120, no. 2, pp. 326-344, 1992.

[51] J. W. Wilson, N. A. Crook, C. K. Mueller, J. Sun, and M. Dixon, "Nowcasting thunderstorms: a status report," Bulletin of the American Meteorological Society, vol. 79, no. 10, pp. 2079-2099, 1998.

[52] Y.-L. Lin, R. D. Farley, and H. D. Orville, "Bulk parameterization of the snow field in a cloud model," Journal of Climate and Applied Meteorology, vol. 22, no. 6, pp. 1065-1092, 1983.

[53] W.-K. Tao, J. Simpson, and M. McCumber, "An ice-water saturation adjustment," Monthly Weather Review, vol. 117, no. 1, pp. 231-235, 1989.

[54] G. Thompson, P. R. Field, R. M. Rasmussen, and W. D. Hall, "Explicit forecasts of winter precipitation using an improved bulk microphysics scheme. Part II: implementation of a new snow parameterization," Monthly Weather Review, vol. 136, no. 12, pp. 5095-5115, 2008.

[55] H. Hall, G. Thompson, and V. Tatarskii, "Impact of cloud microphysics on the development of trailing stratiform 
precipitation in a simulated squall line: comparison of oneand two-moment schemes," Monthly Weather Review, vol. 137, no. 3, pp. 991-1007, 2009.

[56] S.-Y. Hong and J.-O. J. Lim, "The WRF single-moment 6-class microphysics scheme (WSM6)," Journal of the Korean Meteorological Society, vol. 42, no. 2, pp. 129-151, 2006.

[57] E. R. Mansell, C. L. Ziegler, and E. C. Bruning, "Simulated electrification of a small thunderstorm with two-moment bulk microphysics," Journal of the Atmospheric Sciences, vol. 67, no. 1, pp. 171-194, 2010.

[58] S. A. Rutledge and P. Hobbs, "The mesoscale and Microscale structure and organization of clouds and precipitation in midlatitude cyclones. VIII: a model for the "Seeder-Feeder" process in warm-frontal rainbands," Journal of the Atmospheric Sciences, vol. 40, no. 5, pp. 1185-1206, 1983.

[59] R. A. Houze Jr., P. V. Hobbs, P. H. Herzegh, and D. B. Parsons, "Size distributions of precipitation particles in frontal clouds," Journal of the Atmospheric Sciences, vol. 36, no. 1, pp. 156-162, 1979.

[60] G. Parsons, R. M. Rasmussen, and K. Manning, "Explicit forecasts of winter precipitation using an improved bulk microphysics scheme. Part I: description and sensitivity analysis," Monthly Weather Review, vol. 132, no. 2, pp. 519542, 2004.

[61] P. Field, R. Hogan, P. Brown et al., "Parametrization of iceparticle size distributions for mid-latitude stratiform cloud," Quarterly Journal of the Royal Meteorological Society, vol. 131, no. 609, pp. 1997-2017, 2005.

[62] C. Marzban, S. Sandgathe, H. Lyons, and N. Lederer, “Three spatial verification techniques: cluster analysis, variogram, and optical flow," Weather and Forecasting, vol. 24, no. 6, pp. 1457-1471, 2009.

[63] C. Lederer and G. C. Craig, "A displacement-based error measure applied in a regional ensemble forecasting system," Monthly Weather Review, vol. 135, no. 9, pp. 3248-3259, 2007.

[64] C. Marzban and S. Sandgathe, "Optical flow for verification," Weather and Forecasting, vol. 25, no. 5, pp. 1479-1494, 2010.

[65] S. Baker and I. Matthews, "Lucas-kanade 20 years on: a unifying framework," International Journal of Computer Vision, vol. 56, no. 3, pp. 221-255, 2004.

[66] B. D. Lucas and T. Kanade, "An iterative image registration technique with an application to stereo vision," in Proceedings of the 7th International Joint Conference on Artificial Intelligence, San Francisco, CA, USA, pp. 121-130, 1981.

[67] R. Rogers, S. Chen, J. Tenerelli et al., "A numerical study of the impact of vertical shear on the distribution of rainfall in Hurricane Bonnie (1998)," Monthly Weather Review, vol. 131, no. 8, 2003.

[68] A. P. Khain, K. D. Beheng, A. Heymsfield et al., "Representation of microphysical processes in cloud-resolving models: spectral (bin) microphysics versus bulk parameterization," Reviews of Geophysics, vol. 53, no. 2, pp. 247-322, 2015.

[69] M. S. Deshpande, S. Pattnaik, and P. S. Salvekar, "Impact of cloud parameterization on the numerical simulation of a super cyclone," Annales Geophysicae, vol. 30, no. 5, pp. 775-795, 2012.

[70] S. A. Braun, "High-resolution simulation of Hurricane Bonnie (1998). Part II: water budget," Journal of the Atmospheric Sciences, vol. 63, no. 1, pp. 43-64, 2006.

[71] D. J. Cecil and E. J. Zipser, "Reflectivity, ice scattering, and lightning characteristics of hurricane eyewalls and rainbands. Part II: intercomparison of observations," Monthly Weather Review, vol. 130, no. 4, pp. 785-801, 2002.
[72] B. Reinhart, H. Fuelberg, R. Blakeslee et al., "Understanding the relationships between lightning, cloud microphysics, and airborne radar-derived storm structure during hurricane Karl (2010)," Monthly Weather Review, vol. 142, no. 2, pp. 590-605, 2014.

[73] M. P. Meyers, P. J. DeMott, and W. R. Cotton, "New primary ice-nucleation parameterizations in an explicit cloud model," Journal of Applied Meteorology, vol. 31, no. 7, pp. 708-721, 1992.

[74] C. Liu, K. Ikeda, G. Thompson, R. Rasmussen, and J. Dudhia, "High-resolution simulations of wintertime precipitation in the Colorado Headwaters region: sensitivity to physics parameterizations," Monthly Weather Review, vol. 139, no. 11, pp. 3533-3553, 2011.

[75] J. D. McMillen and W. J. Steenburgh, "Impact of microphysics parameterizations on simulations of the 27 october 2010 great salt lake-effect snowstorm," Weather and Forecasting, vol. 30, no. 1, pp. 136-152, 2015.

[76] W. A. Cooper, "Ice initiation in natural clouds," Precipitation Enhancement-A Scientific Challenge, vol. 43, no. 12, pp. 29-32, 1986.

[77] E. Bigg, "The formation of atmospheric ice crystals by the freezing of droplets," Quarterly Journal of the Royal Meteorological Society, vol. 79, no. 5, pp. 510-519, 1953.

[78] S.-Y. Hong, J. Dudhia, and S.-H. Chen, "A revised approach to ice microphysical processes for the bulk parameterization of clouds and precipitation," Monthly Weather Review, vol. 132, no. 1, pp. 103-120, 2004.

[79] M. Rajeevan, A. Kesarkar, S. B. Thampi, T. N. Rao, B. Radhakrishna, and M. Rajasekhar, "Sensitivity of WRF cloud microphysics to simulations of a severe thunderstorm event over Southeast India," Annales Geophysicae, vol. 28, no. 2, pp. 603-619, 2010.

[80] R. F. Adler, H.-Y. M. Yeh, N. Prasad, W.-K. Tao, and J. Simpson, "Microwave simulations of a tropical rainfall system with a three-dimensional cloud model," Journal of Applied Meteorology, vol. 30, no. 7, pp. 924-953, 1991.

[81] E. A. Smith, H. J. Cooper, X. Xiang, A. Mugnai, and G. J. Tripoli, "Foundations for statistical-physical precipitation retrieval from passive microwave satellite measurements. Part I: brightness-temperature properties of a time-dependent cloud-radiation model," Journal of Applied Meteorology, vol. 31, no. 6, pp. 506-531, 1992.

[82] G. Hong, G. Heygster, J. Miao et al., "Sensitivity of microwave brightness temperatures to hydrometeors in a tropical deep convective cloud system at 89-190 GHz," Radio Science, vol. 40, no. 4, pp. 1-13, 2005.

[83] M. Yanai, "Formation of tropical cyclones," Reviews of Geophysics, vol. 2, no. 2, pp. 367-414, 1964.

[84] Y. Wang and C.-C. Wu, "Current understanding of tropical cyclone structure and intensity changes? a review," Meteorology and Atmospheric Physics, vol. 87, no. 4, pp. 257-278, 2004.

[85] R. A. Anthes, "The dynamics and energetics of mature tropical cyclones," Reviews of Geophysics, vol. 12, no. 3, pp. 495-522, 1974.

[86] B. K. Mahala, P. K. Mohanty, and B. K. Nayak, "Impact of microphysics schemes in the simulation of cyclone phailinusing WRF model," Procedia Engineering, vol. 116, no. 1, pp. 655-662, 2015.

[87] T. N. Krishnamurti, K. S. Yap, and D. K. Oosterhof, "Sensitivity of tropical storm forecast to radiative destabilization," Monthly Weather Review, vol. 119, no. 9, pp. 2176-2205, 1991. 
[88] G. C. Craig, "Numerical experiments on radiation and tropical cyclones," Quarterly Journal of the Royal Meteorological Society, vol. 122, no. 530, pp. 415-422, 2010.

[89] J. Guo, H. Liu, F. Wang et al., "Three-dimensional structure of aerosol in China: a perspective from multi-satellite observations," Atmospheric Research, vol. 178-179, no. 9, pp. 580-589, 2016.

[90] T. Chen, J. Guo, Z. Li et al., "ACloudSatPerspective on the cloud climatology and its association with aerosol perturbations in the vertical over eastern China," Journal of the Atmospheric Sciences, vol. 73, no. 9, pp. 3599-3616, 2016. 

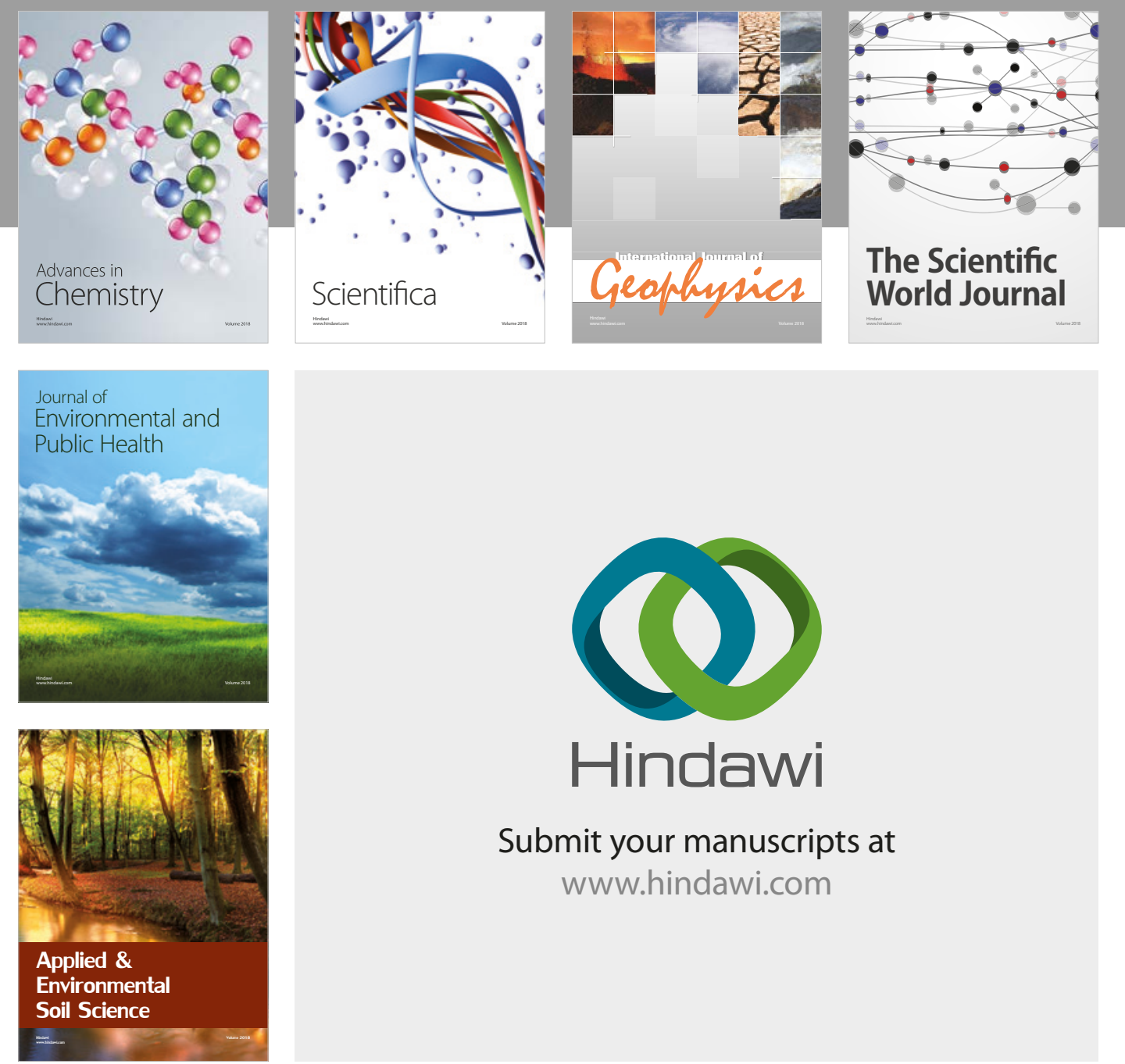

The Scientific

\section{World Journal}
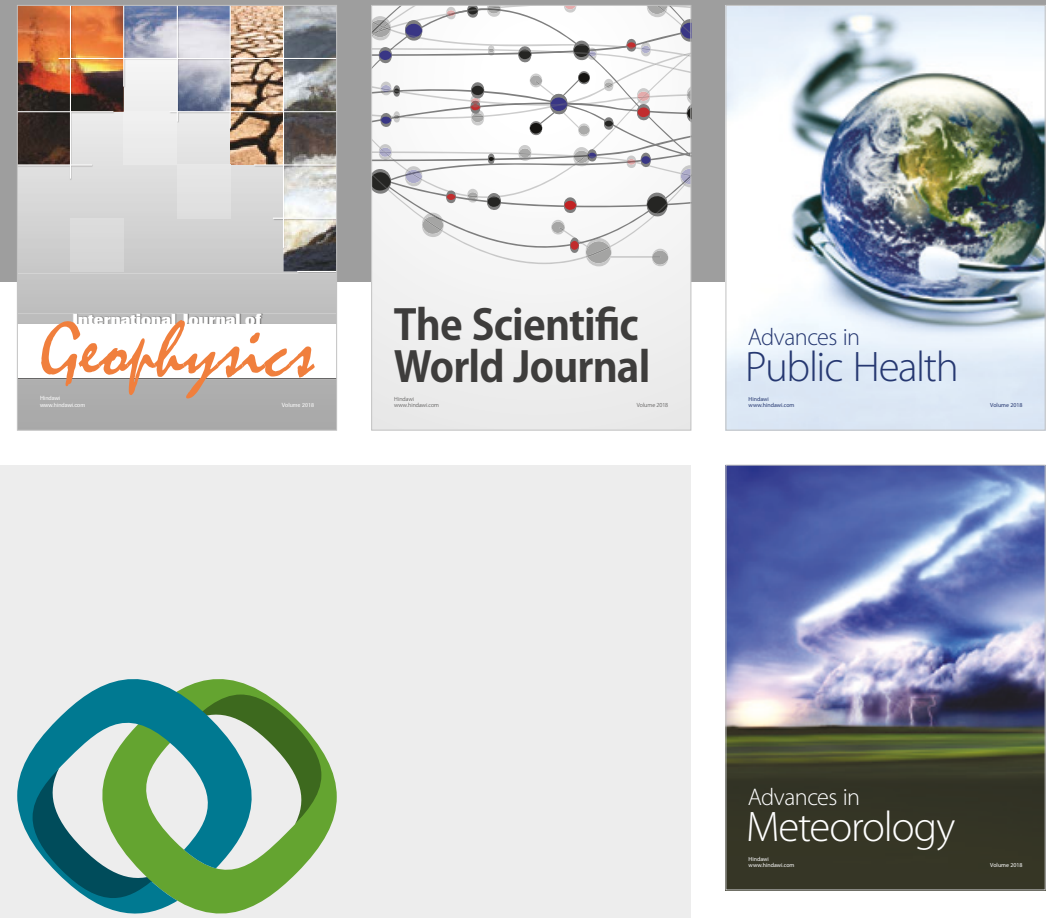

Advan

Public Health

\section{Hindawi}

Submit your manuscripts at

www.hindawi.com
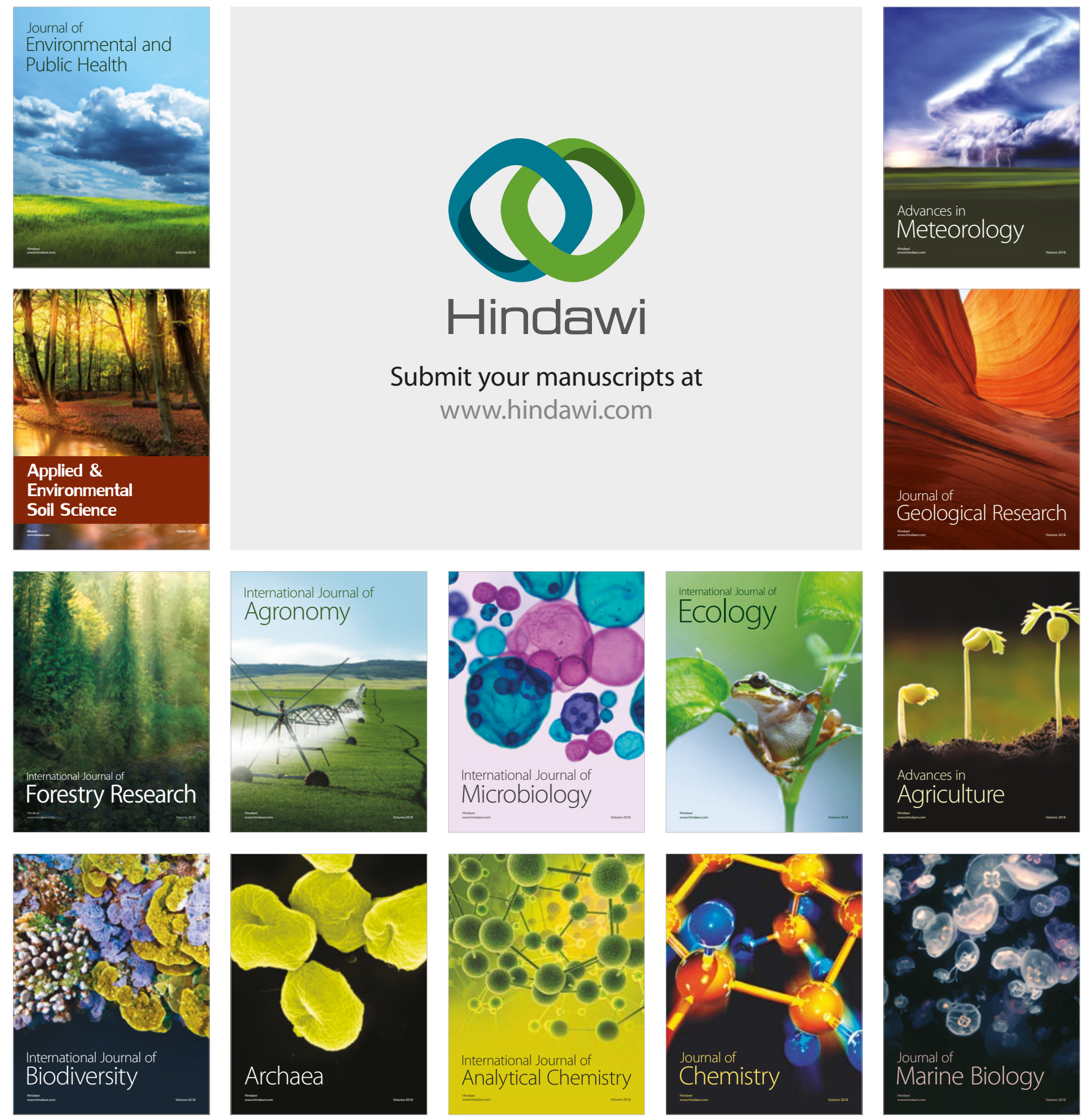